\title{
CASA AYMARA EN ENQUELGA ${ }^{1}$
}

\author{
Václav Šolc
}

La población del Altiplano chileno es evidentemente muy antigua. Toda esta región es muy poco conocida e investigada, pero las evidencias arqueológicas comprueban que la morfología espacial de cuencas lacustres fueron favorables a los sitios de cazadores y recolectores, quizás desde 10.000 años antes de J.C. ${ }^{1}$. En tiempos después de J.C. empieza en esta región un movimiento hacia la cultura elevada del Altiplano, hacia la cultura Titicaca-Desaguadero. Los grupos aislados forman pequeñas comunidades de pastores con cultivos de papas y de la quinua (Chenopodium, en aymara hupja), con un movimiento constante en las áreas favorables del Altiplano (Figura 1). Estos grupos bajo la presión de las culturas del Altiplano (región de Bolivia de hoy día) que conocemos mejor como grupos de los aymaras, existen hasta hoy día-según los testimonios de la arqueología.

Tuvimos la posibilidad de realizar estudios, en colaboración con la Universidad de Chile, en la época de 1968-1969 en el Altiplano mencionado, en el interior de Iquique, en la región de Isluga (entre el volcán de Isluga -altura de 5.538 m- y el salar de Coipasa). He pasado algunos meses en un pueblito que se llama Enquelga (altura de $4.100 \mathrm{~m}$ ), seis kilómetros al oeste del pueblo sagrado de Isluga. Es una población fija, con viviendas en lugares donde hay pasto. Con mucha probabilidad se formó desde unos caseríos dispersos (en la región existen restos de ellos), bajo la influencia de las autoridades -coloniales y postcoloniales- un pueblito fijo. A la población de Enquelga pertenecen también de manera bastante independiente otras dos comunidades más chicas, Caraguano y Chapicollo.

Razones económicas obligan a los pobladores a salir del pueblo por períodos cortos o más largos. La primera razón es su trabajo principal, la ganadería, el pastoreo de los animales, llamas y ovejas. También tienen que salir del pueblo para ir algunas veces a Camiña (un valle subcordillerano típico, situado más abajo, al oeste, a una distancia de dos días de camino). Con este lugar tiene Enquelga relaciones económicas bastante estrechas e importantes. Entre las dos poblaciones existe un sistema permanente de intercambio -o canje de mercaderías y materias primas. Los de Enquelga traen para Camiña animales para carne, cueros y lana para tejidos; desde Camiña se abastecen con productos agrícolas. Para Camiña se van también a trabajar en la cosecha del maíz y otros productos agrícolas como ayudantes o trabajadores pagados para ganar un poco de plata. En los últimos años la gente del Altiplano empieza a establecerse en el mismo valle como habitantes permanentes, reemplazando despacio a los habitantes originales que se van a las ciudades. Además los dirigentes de las tradicionales fiestas de Camiña

1 Nota de los editores: este artículo fue publicado por el Dr. Šolc, de origen checo, en 1975 en Annals of Náprstkovo Muzeum 8 , pp. 111-146. La idea de reimprimirlo surgió a consecuencia que Jorge Hidalgo encontró, en 1981, en la ex sede Arica de la Universidad de Chile un conjunto de impresiones fotográficas en blanco y negro con un listado explicativo que el autor entregó a la Universidad de Chile a comienzos de los años setenta. Este archivo formaba parte de los resultados de sus expediciones antropológicas a las zonas mapuche y aymara y derivó en la publicación del artículo en comento. Una copia del mismo se envió al Museo de Praga a modo de intercambio. Con este material, a comienzos del año 2000 iniciamos los contactos con dicho Museo, con la esperanza de tratar directamente con el Dr. Šolc y para ello tuvimos la amable colaboración de Drahomira Srytrova Tomasova, su compatriota, quien nos ha acompañado en todo el proceso de reedición. En el verano del año 2000 visitaron el Museo, Lautaro Núnez, Hans Gundermann y Calogero Santoro para tratar el tema.

El 27 de junio de 2002 recibimos autorización del director del Národní Muzeum Náprstkovo Muzeum asijských, afrických a amerických kultur, Dr. Jana Součková, para publicar una edición revisada del artículo. Esto fue ratificado en abril de 2008 por la Dra. Blanka M. Remešová, Directora del Museo y Monika Bad’urová, curadora del Departamento de Etnografía de quienes obtuvimos, en el 2010, una copia digital de las fotografías originales. Por lo tanto, todas las imágenes que se presentan fueron realizadas por el Dr. Šolc. El texto fue corregido y mejorado en la sintaxis de español cuidando de no transgredir la intención original del autor, quien escribió en castellano no siendo su idioma original. Se incorporaron también llamados de las figuras y tablas que no existían en la publicación original.

Considerando que esta nota etnográfica sobre la región andina del norte de Chile es un documento poco usual se invitó a varios antropólogos andinos a que comentaran las observaciones del Dr. Šolc en el contexto del desarrollo actual de la antropología. Respondieron la invitación los colegas: Penny Dransat, Juan van Kessel, Hans Gundermann, Manuel Mamani y Luis Galdames, cuyos comentarios se incluyen a continuación del artículo. 


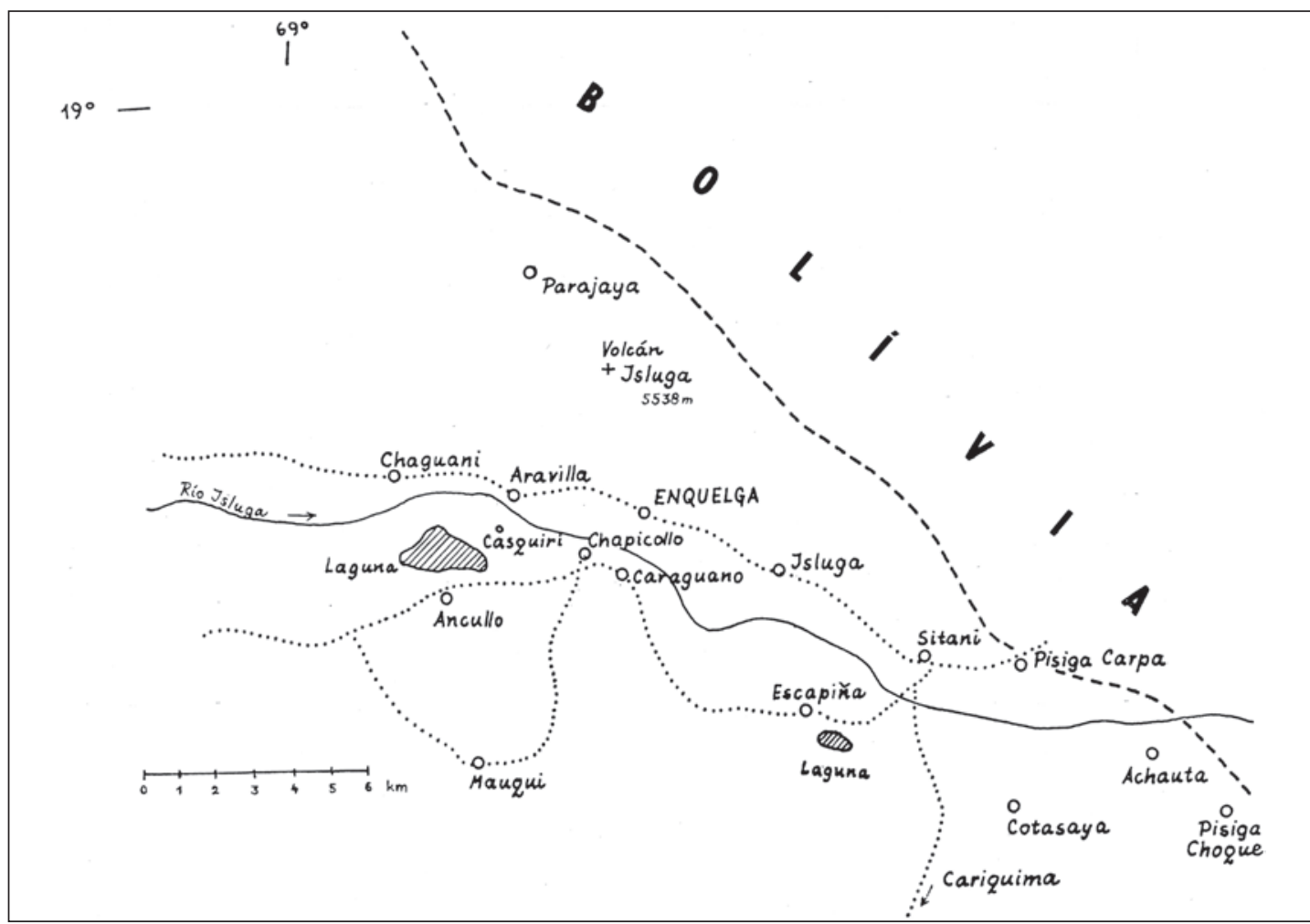

Figura 1. Plano general de las comunidades alrededor de Enquelga.

contratan frecuentemente a la banda musical de Enquelga para tocar durante toda la fiesta.

En Enquelga viven 31 familias con 157 miembros en total. La población del pueblito está dividida en tres grupos, o familias grandes (Figura 2). La familia Castro tiene 22 familias con 97 miembros; familia Mamani 5 familias con 36 miembros, y familia Condori 4 familias con 24 miembros. En el pueblo mismo no hay familias con otro apellido. Las dos poblaciones más chicas ligadas de manera más o menos independiente a Enquelga están pobladas cada cual por una familia grande; en Caraguano viven los Challapas y en Chapicollo los Vilche.

El plano del pueblo mismo constituye aproximadamente un rectángulo prolongado, orientado este-oeste, estrictamente dividido en tres partes, diferentes de tamaño. Cada parte está habitada por miembros de una de las familias mencionadas (Figura 2). A los límites de sus territorios los conoce cada miembro adulto de familia y los respeta perfectamente, especialmente cuando hay que construir una casa nueva por ejemplo para una pareja recién casada (en estos casos mantienen estrictamente la patrilocalidad). Más al este están situadas las casitas de las familias Mamani, en el centro las de los Condori y al oeste las de los Castro. Todas las casas -con excepción de algunas pocas- están orientadas con puertas hacia el este, para tener en la puerta el primer sol de la mañana.

El pueblo mismo no tiene larga historia. Según mis informaciones (informantes: Marcos Castro Challapa, Víctor Mamani, Juan Mamani Castro, Ambrosio Condori García), las casas más antiguas pueden tener alrededor de 120 años de edad. Este dato corresponde a la época en que las autoridades blancas empezaron a formar a las poblaciones de tipo de pueblo, obligando a los indios de abandonar sus viviendas aisladas en los alrededores de los bofedales de pastoreo.

En Enquelga hay casi exclusivamente viviendas de casas particulares, de familias. Como excepción existen solamente:

$1^{\circ}$. La iglesia de San Santiago (santo-patrono de Enquelga), construida de adobes y piedras. Tiene una edad aproximada de 50 años. Según los informantes había otra iglesia, más chica al este del pueblito, afuera de la zona del pueblo. La de hoy día está construida en la zona de los 
Castro. Tiene un campanario al lado del muro, que rodea la iglesia (Figura 3 ).

$2^{\circ}$. La escuela que tiene tres casas (vivienda del profesor, casa para dar clases y despensa). Todas son construidas de adobes y tienen una edad de cuatro años.

$3^{\circ}$. En el pueblo mismo, en la parte de los Castro existe una casa, ahora sin techo y abandonada, construida por Leonardo Raimundo Castro Flores para fiestas, bailes, etc. El dueño vive en Enquelga raras veces y por esto está la casa abandonada. Está construida de adobes y de manera deficiente ${ }^{2}$.

Según el material de construcción se encuentran en el pueblo casas de piedras, que son las más antiguas (hasta 120 años) (Figuras 4 y 5) y las de adobes (Figura 6) las más nuevas (Tabla 1). Según los informantes había en el pueblo hace 45 años solamente dos casas del padre del informante Marcos Castro, tres casas de Guillermo Castro, tres casas de Francisco Condori y cuatro casas de Ramón Mamani, casas de los representantes de las tres familias que forman la población de Elquelga hoy día.

La mayoría de las casas están habitadas. Algunas de las más antiguas, cuyos dueños murieron, están en ruinas, en su mayoría sin techo y sin puertas. En algunas, que se encuentran en ruinas no hay posibilidad de identificar con seguridad el tipo del techo y el material usado. Todo el pueblo está compuesto de 115 casas. Sin edificios de la escuela y sin la iglesia, este número disminuye a un total de 111 casas (Tabla 2).

Según el material utilizado para la construcción existen en Enquelga 80 casas hechas de adobes, 22 de piedras (las más antiguas) y 9 casas de tipo de transición, hechas de una combinación de piedras y adobes. De estas últimas la parte baja es de piedras y la parte más alta es de adobes (Figura 7). Esto quiere decir que los constructores probablemente han utilizado unos restos de casas más antiguas.

Según la forma de los muros encontramos en el pueblo una mayoría grande de tipo de construcción más antigua, típica para todas las casas hechas de piedras sin excepción, la forma de muros ligeramente inclinados hacia adentro. Solamente un número pequeño de 12 casas -todas de adobes- tienen sus muros estrictamente verticales. Cierto número de muros de las casas están provistos de un revoque de barro simple, alisado de manera primitiva. Este revoque tienen 43 casas y solamente 9 están pintadas, en su mayoría con color blanco (Figura 8).
El plano de las casas es rectangular en una mayoría absoluta de 109 casos. Sólo dos casas tienen un plano irregular; una por razones del espacio limitado por otras casas y otra (en el tiempo de mi investigación sobre construcción) tenía una esquina cortada por influencia de lo que el dueño y constructor vio en la ciudad de Iquique. La misma casa está construida con dos piezas. Esto es una excepción en el total de casas con una sola pieza (110 casas).

Como material para cubrir el techo sirve sin excepción una especie de paja brava (99 casos). Aun cuando no había posibilidad de identificar con una seguridad absoluta el tipo de construcción de materiales [materiales de construcción] utilizados en algunos casos de techos caídos y desaparecidos, se puede juzgar con mayor probabilidad que en el pueblo de Enquelga no existía otro tipo de cubiertas.

Según la forma de construcción de techos hemos constatado 97 casos de techos de dos agua, tres techos de un agua (Figura 9), un techo irregular de tres aguas (en el caso de una casa ya antes mencionada, irregular por falta de espacio) y solamente un techo de cuatro aguas. Esto es un fenómeno bastante interesante, especialmente en el caso de casas más antiguas. En otros lugares, como por ejemplo en el pueblo de Chapiquiña, al interior de Arica, que tiene casi la misma edad hemos visto ${ }^{3}$ que las casas más antiguas, construidas de piedras, tienen casi sin excepción la forma de un techo de cuatro aguas.

Cada casa tiene una puerta, prácticamente casi siempre de una hoja. Las puertas de las casas más antiguas son más chicas, bajas y estrechas, construidas de manera bastante primitiva. La madera es de una especie de cactus grande, llamado cardón (Figura 10), cubiertas originalmente con cuero seco de llama (ahora con metal delgado de unas latas de alcohol o aceite cortadas). Las casas más nuevas tienen ahora puertas un poco más grandes, de madera, traídas desde Bolivia o desde Iquique o Pisagua. Las ventanas son hasta ahora una excepción en las casas de Enquelga (Figura 11); se ven solamente en las construcciones más nuevas. Son generalmente ventanas chicas, situadas siempre a bastante altura (Figura 8). Rara vez tienen vidrio; algunas veces contraventanas de tablas de madera. En algunas casas constatamos un fenómeno muy interesante: los dueños de las casas primero hicieron una ventana con vidrio y después la taparon con 


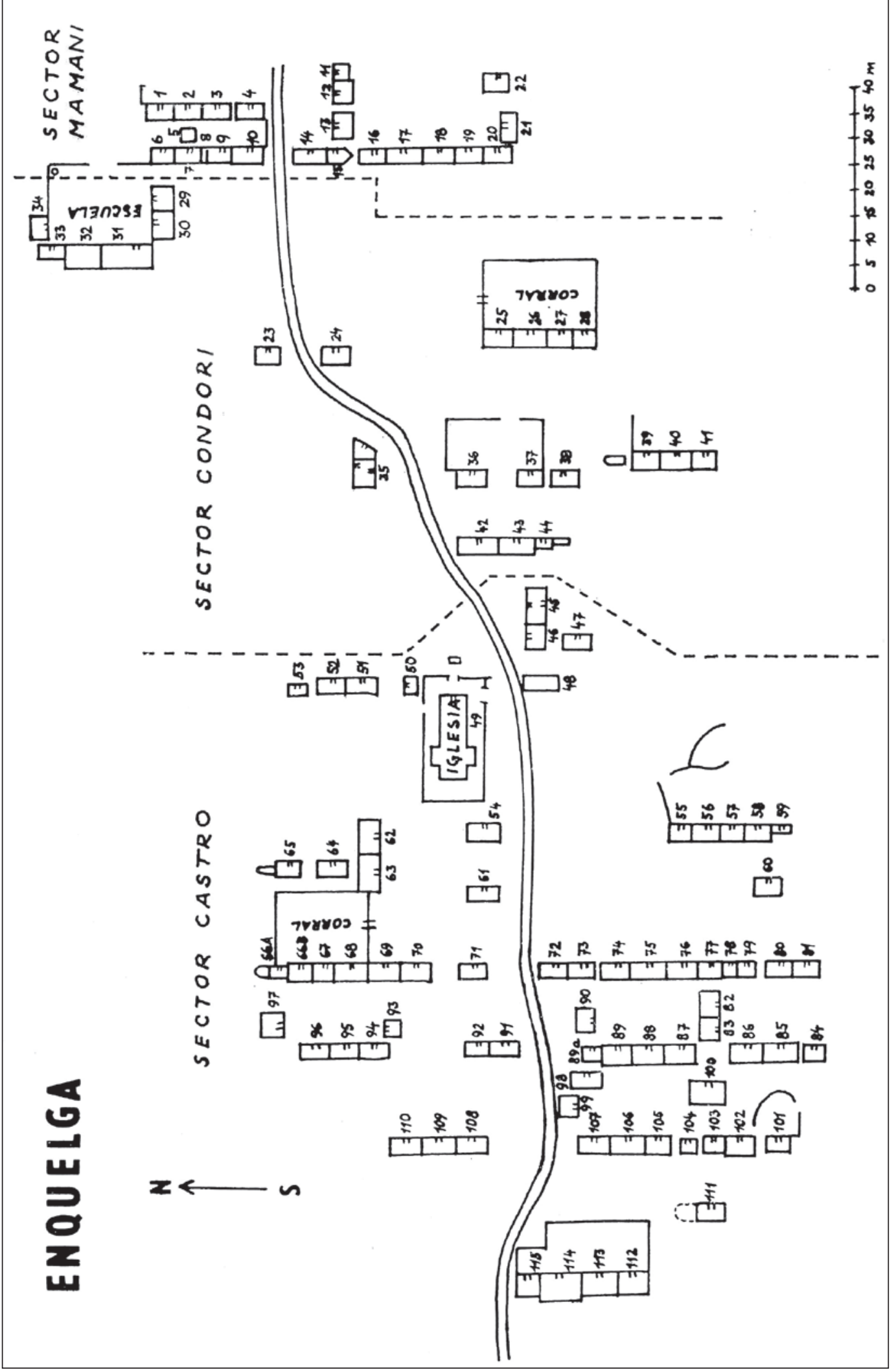


Tabla 1. Dimensiones y carácterísticas de las casas

\begin{tabular}{|c|c|c|c|c|c|c|c|c|c|c|}
\hline \multicolumn{11}{|c|}{ Dimensiones } \\
\hline Casa $\mathrm{N}^{\mathrm{o}}$ & Material & Techo & Longit. & Anchura & Altura & Revoque & Pintura & Cruz & Ventanas & Sirve como \\
\hline 1 & A & 2 & 6,0 & 3,1 & 2,1 & $X$ & & $X$ & & $\mathrm{M}$ \\
\hline 2 & $\mathrm{~A}$ & 2 & 6,2 & 3,1 & 2,1 & $\mathrm{X}$ & & & & M \\
\hline 3 & A & 2 & 5,2 & 3,1 & 2,1 & $\mathrm{X}$ & & $X$ & & $\mathrm{D}$ \\
\hline 4 & A & 2 & 5,4 & 2,9 & 2.0 & & & & 1 & $\mathrm{C}$ \\
\hline 5 & $\mathrm{~A}+$ & & 4,2 & 2,2 & 1,4 & no & - & terminada & & \\
\hline 6 & $\mathrm{~A}+$ & 2 & 3,9 & 3,3 & 2,0 & & & & & $\mathrm{C}$ \\
\hline 7 & $\mathrm{~A}$ & 2 & 5,4 & 3,2 & 2,4 & & & & & $\mathrm{D} / \mathrm{M}$ \\
\hline 8 & $\mathrm{~A}+$ & & & & & no & - & terminada & & $\mathrm{C}$ \\
\hline 9 & $\mathrm{~A}$ & 2 & 5,2 & 3,3 & 2.0 & $\mathrm{X}$ & $\mathrm{X}$ & $\mathrm{X}$ & $1 / \mathrm{T}$ & $\mathrm{D}$ \\
\hline 10 & $\mathrm{~A}$ & 2 & 6,0 & 3,5 & 2.0 & $\mathrm{X}$ & $\mathrm{X}$ & $X$ & & M \\
\hline 11 & $\mathrm{~A}+$ & 2 & 3,6 & 2,8 & 1,4 & & & & $1 / \mathrm{T}$ & $\mathrm{C}$ \\
\hline 12 & A & 2 & 5,75 & 3,1 & 1,8 & & & & & $\mathrm{D}$ \\
\hline 13 & A & 2 & 6,0 & 3,5 & 2,05 & $\mathrm{X}$ & $\mathrm{X}$ & & $1 / \mathrm{V}$ & M \\
\hline 14 & A & 2 & 7,5 & 3,8 & 2,5 & $\mathrm{X}$ & & $X$ & $2 / \mathrm{T}$ & M \\
\hline 15 & A & 2 & 4,5 & 3,8 & 2,5 & $X$ & & & & $\mathrm{C}$ \\
\hline 16 & A & 2 & 5,5 & 3,8 & 2,4 & $X$ & & $X$ & & $\mathrm{D}$ \\
\hline 17 & A & 2 & 8,2 & 3,8 & 2,4 & $X$ & & $X$ & 2/T,M & D \\
\hline 18 & A & 2 & 5,8 & 3,8 & 2,05 & $X$ & & & & M \\
\hline 19 & A & 2 & 5,3 & 3,8 & 2,05 & $X$ & & $X$ & & M \\
\hline 20 & A & 2 & 5,55 & 3,5 & 2,0 & $X$ & & & & $\mathrm{D}$ \\
\hline 21 & A & 2 & 6,15 & 3,55 & 2,1 & $X$ & $X$ & $\mathrm{X}$ & $1 / \mathrm{T}$ & \\
\hline 22 & A & 2 & 5,0 & 3,25 & 2,0 & & & & vent & $\mathrm{C}$ \\
\hline 23 & A & 2 & 4,1 & 2,55 & 1,7 & & & & vent & $\mathrm{C}$ \\
\hline 24 & A & 2 & 5,8 & 3,6 & 2,0 & & & $X$ & & D \\
\hline 25 & A & 1 & 5,7 & 3,95 & $3,3 / 2,1$ & $X$ & $X$ & & $1 / \mathrm{M}$ & M \\
\hline 26 & A & 2 & 6,4 & 3,15 & 2,0 & X & $X$ & $X$ & $1 / \mathrm{T}$ & M \\
\hline 27 & $\mathrm{~A} / \mathrm{P}$ & 2 & 3,95 & 3,15 & 2,0 & $X$ & $X$ & & $1 / \mathrm{T}$ & $\mathrm{D}$ \\
\hline 28 & $\mathrm{~A} / \mathrm{P}$ & 2 & 4,1 & 2,0 & 2,0 & & & & vent & $\mathrm{C}$ \\
\hline 35 & $\mathrm{~A}+$ & & 9,7 & 3,5 & & en cons & ucción & & & $\mathrm{D} / \mathrm{M}$ \\
\hline 36 & $\mathrm{~A} / \mathrm{P}$ & 2 & 6,4 & 3,4 & 2,3 & $X$ & $X$ & $X$ & $1 / \mathrm{M}$ & M \\
\hline 37 & $\mathrm{P}$ & 2 & 6,0 & 3,5 & 2,2 & $X$ & $X$ & $X$ & & D \\
\hline 38 & $\mathrm{P}+$ & 2 & 5,7 & 2,8 & 1,8 & & & & & $\mathrm{C}$ \\
\hline 39 & $\mathrm{P}+$ & 2 & 5,0 & 2,4 & 2,0 & & & & & $\mathrm{C}$ \\
\hline 40 & $\mathrm{P}+$ & 2 & 6,5 & 2,4 & 2,2 & & & & & $\mathrm{D}$ \\
\hline 41 & $\mathrm{P}$ & 2 & 4,8 & 2,8 & 2,0 & & & & & M \\
\hline 42 & A & 2 & 7,7 & 3,4 & 2,2 & X & & & $1 / \mathrm{M}$ & $\mathrm{D}$ \\
\hline 43 & A & 2 & 7,05 & 3,4 & 2,2 & $X$ & & $X$ & $2 / \mathrm{T}$ & Para visitas \\
\hline 44 & $\mathrm{P}$ & 2 & 2,8 & 2,0 & 1,35 & & & & & C \\
\hline 45 & A & 1 & 6,8 & 3,1 & $2,7 / 2,1$ & $X$ & & & $1 / \mathrm{T}$ & M \\
\hline 46 & A & 2 & 5,9 & 3,25 & 2,8 & $\mathrm{X}$ & & & & M \\
\hline 47 & $\mathrm{~A}+$ & & 5,7 & 3,3 & & no & - & terminada & & $\mathrm{C}$ \\
\hline 48 & A & 2 & 5,9 & 3,4 & 2,2 & $X$ & & $X$ & & M \\
\hline 51 & A & 2 & 5,9 & 3,6 & 2,35 & $X$ & & $X$ & & $\mathrm{D}$ \\
\hline 52 & A & 2 & 5,3 & 3,63 & 2,35 & $\mathrm{X}$ & & $\mathrm{X}$ & & M \\
\hline 53 & A & 2 & 4,5 & 2,75 & 1,7 & & & & vent & $\mathrm{C}$ \\
\hline 54 & A & 2 & 6,65 & 3,5 & 2,3 & $\mathrm{X}$ & & $X$ & & M \\
\hline 55 & $\mathrm{~A} / \mathrm{P}$ & 2 & 5,0 & 2,6 & 1,85 & & & & & $\mathrm{C} / \mathrm{D}$ \\
\hline 56 & $\mathrm{~A} / \mathrm{P}$ & 2 & 5,1 & 2,6 & 1,9 & & & $X$ & & $\mathrm{D}$ \\
\hline 57 & A & 2 & 5,0 & 2,6 & 2,0 & $\mathrm{X}$ & & $X$ & & M \\
\hline 58 & $\mathrm{~A}$ & 2 & 5,0 & 2,6 & 1,85 & $\mathrm{X}$ & & $\mathrm{X}$ & & $\mathrm{D}$ \\
\hline 59 & $\mathrm{P}$ & 2 & 2,75 & 2,5 & 1,4 & & & & & $\mathrm{C}$ \\
\hline 60 & $\mathrm{~A}$ & 2 & 4,9 & 3,0 & 1,8 & & & $X$ & vent & $\mathrm{C}$ \\
\hline 61 & $\mathrm{~A}$ & 2 & 5,05 & 2,8 & 1,85 & & & & & $\mathrm{C}$ \\
\hline 62 & A & 2 & 7,6 & 3,5 & 2,2 & & & $X$ & 2 & Para visitas \\
\hline 63 & A & 2 & 6,2 & 3,5 & 2,3 & & & $\mathrm{X}$ & & M \\
\hline
\end{tabular}


Continuación Tabla 1

\begin{tabular}{|c|c|c|c|c|c|c|c|c|c|c|}
\hline \multicolumn{11}{|c|}{ Dimensiones } \\
\hline Casa $\mathrm{N}^{\circ}$ & Material & Techo & Longit. & Anchura & Altura & Revoque & Pintura & Cruz & Ventanas & Sirve como \\
\hline 64 & A & 2 & 6,2 & 3,3 & 2,1 & & & $\mathrm{X}$ & & M \\
\hline 65 & A & 2 & 4,8 & 2,5 & 1,8 & & & & & $\mathrm{C}$ \\
\hline $66 \mathrm{~A}$ & A & 2 & 2,5 & 2,5 & 1,25 & & & & & $\mathrm{C}$ \\
\hline $66 \mathrm{~B}$ & A & 2 & 4,5 & 3,35 & 2,1 & $\mathrm{X}$ & & $X$ & & $\mathrm{D}$ \\
\hline 67 & A & 2 & 3,8 & 3,95 & 2,1 & $\mathrm{X}$ & & $X$ & & $\mathrm{M} / \mathrm{D}$ \\
\hline 68 & A & 2 & 6,7 & 3,95 & 2,1 & $\mathrm{X}$ & & $\mathrm{X}$ & & M \\
\hline 69 & A & 2 & 6,2 & 3,95 & 2,1 & & & $X$ & & $\mathrm{D}$ \\
\hline 70 & A & 2 & 6,6 & 3,95 & 1,9 & & & & & M \\
\hline 71 & A & 2 & 5,7 & 2,8 & 1,75 & & & & vent & $\mathrm{C}$ \\
\hline 72 & $\mathrm{~A}+$ & 2 & 5,8 & 3,3 & 2,05 & $\mathrm{X}$ & sin techo & & & $\mathrm{C}$ \\
\hline 73 & $\mathrm{~A}$ & 2 & 5,7 & 3,3 & 2,2 & & & $X$ & & M \\
\hline 74 & A & 2 & 5,3 & 2,1 & 1,2 & $\mathrm{X}$ & & $X$ & & M \\
\hline 75 & $\mathrm{~A} / \mathrm{P}+$ & 2 & 8,0 & 3,3 & 2,0 & $\mathrm{X}$ & sin techo & & vent & Para fiestas \\
\hline 76 & $\mathrm{P}$ & 2 & 6,1 & 3,3 & 2,25 & & X & & & M \\
\hline 77 & $\mathrm{P} / \mathrm{A}$ & 2 & 5,2 & 3,3 & 2,1 & $X$ & & $X$ & & $\mathrm{D}$ \\
\hline 78 & $\mathrm{P}$ & 3 & 2,3 & 2,9 & 1,45 & & & & & $\mathrm{C}$ \\
\hline 79 & $\mathrm{P}+$ & 2 & 3,1 & 2,9 & 1,8 & & & & & $\mathrm{C}$ \\
\hline 80 & $\mathrm{~A} / \mathrm{P}$ & 2 & 4,75 & 3,0 & 2,15 & & & & $1 / \mathrm{T}$ & $\mathrm{M}$ \\
\hline 81 & $\mathrm{~A} / \mathrm{P}$ & 2 & 5,25 & 3,0 & 2,15 & & & & $1 / \mathrm{T}$ & $\mathrm{D}$ \\
\hline 82 & A & 2 & 5,15 & 3,0 & 2,15 & $X$ & & $X$ & $1 / \mathrm{T}$ & $\mathrm{D}$ \\
\hline 83 & A & 2 & 5,4 & 3,0 & 2,15 & & & $X$ & & M \\
\hline 84 & A & 2 & 4,5 & 2,7 & 1,5 & & & & vent & $\mathrm{C}$ \\
\hline 85 & $\mathrm{~A} / \mathrm{P}$ & 2 & 5,95 & 3,25 & 2,25 & & & $X$ & & $\mathrm{D}$ \\
\hline 86 & $\mathrm{~A} / \mathrm{P}$ & 2 & 5,6 & 3,25 & 2,25 & & & $X$ & & $\mathrm{M}$ \\
\hline 87 & $\mathrm{~A} / \mathrm{P}$ & 2 & 6,2 & 3,3 & 2,15 & $X$ & & $X$ & & $\mathrm{M}$ \\
\hline 88 & $\mathrm{~A}$ & 2 & 5,7 & 3,3 & 2,15 & & & & & M \\
\hline 89 & $\mathrm{~A} / \mathrm{P}$ & 2 & 5,5 & 3,3 & 1,8 & & & & & $\mathrm{C}$ \\
\hline $89 a$ & $\mathrm{P}+$ & 2 & 3,15 & 2,9 & & $\sin$ & echo & & & $\mathrm{C}$ \\
\hline 90 & A & 2 & 5,7 & 3,3 & 2,25 & $X$ & & $X$ & & D \\
\hline 91 & A & 2 & 6,0 & 3,1 & 2,1 & $X$ & $X$ & $X$ & & $\mathrm{D}$ \\
\hline 92 & A & 2 & 5,55 & 2,8 & 1,75 & & & & & $\mathrm{C}$ \\
\hline 93 & A & 2 & 4,4 & 2,8 & 1,7 & & & & & $\mathrm{C}$ \\
\hline 94 & A & 2 & 6,2 & 3,4 & 2,25 & $X$ & & $X$ & & $\mathrm{M} / \mathrm{D}$ \\
\hline 95 & A & 2 & 6,4 & 3,4 & 2,25 & $X$ & & $X$ & & $\mathrm{M}$ \\
\hline 96 & A & 2 & 6,15 & 3,4 & 2,3 & $X$ & & $X$ & & $\mathrm{M}$ \\
\hline 97 & A & 2 & 4,8 & 2,9 & 2,1 & & & & & $\mathrm{C}$ \\
\hline 98 & A & 2 & 5,05 & 3,0 & 2,0 & & & & & $\mathrm{M} / \mathrm{D}$ \\
\hline 99 & A & 2 & 4,5 & 2,9 & 2,1 & & & & & $\mathrm{C}$ \\
\hline 100 & $\mathrm{P} / \mathrm{A}$ & 2 & 7,0 & 3,4 & 2,1 & & & & & M \\
\hline 101 & A & 2 & 4,5 & 2,75 & 1,8 & & & $X$ & & $\mathrm{C}$ \\
\hline 102 & A & 2 & 6,3 & 3,25 & 2,2 & $X$ & $X$ & $X$ & & $\mathrm{D}$ \\
\hline 103 & A & 2 & 4,65 & 2,95 & 1,2 & & & $X$ & & $\mathrm{M}$ \\
\hline 104 & $\mathrm{P}$ & 4 & 3,4 & 2,25 & 1,3 & & & & & $\mathrm{C}$ \\
\hline 105 & A & 2 & 6,3 & 3,2 & 2,6 & & & $X$ & $1 / \mathrm{T}$ & $\mathrm{D}$ \\
\hline 106 & A & 2 & 6,1 & 3,27 & 2,25 & $X$ & & $X$ & & M \\
\hline 107 & A & 2 & 5,5 & 3,27 & 2,25 & & & $X$ & $1 / \mathrm{M}$ & M \\
\hline 108 & A & 2 & 5,7 & 3,0 & 2,0 & & & $X$ & & $\mathrm{M}$ \\
\hline 109 & $\mathrm{P}+$ & 2 & 5,6 & 3,0 & 1,75 & & sin techo & & & \\
\hline 110 & $\mathrm{P}+$ & 2 & 5,4 & 3,0 & 1,75 & & sin techo & & & M \\
\hline 111 & $\mathrm{P}+$ & 2 & 6,0 & 2,8 & 1,8 & ruina & sin techo & & & \\
\hline 112 & $\mathrm{P}+$ & 2 & 5,8 & 3,1 & 1,95 & ruina & sin techo & & & M \\
\hline 113 & $\mathrm{P}$ & 2 & 7,3 & 3,6 & 2,25 & & & & & M \\
\hline 114 & $\mathrm{P}$ & 2 & 7,1 & 3,6 & 2,25 & & & $\mathrm{X}$ & & \\
\hline 115 & $\mathrm{P}$ & 2 & 5,0 & 2,95 & 1,55 & $\mathrm{X}$ & & & & $\mathrm{C}$ \\
\hline
\end{tabular}


Tabla 2. Casas como propiedades

\begin{tabular}{|c|c|c|c|c|c|c|c|c|c|c|}
\hline \multicolumn{11}{|c|}{ Dimensiones } \\
\hline Casa $\mathrm{N}^{\mathrm{o}}$ & \multicolumn{2}{|l|}{ Dueño } & $\begin{array}{l}\text { Casa } \\
\text { Total }\end{array}$ & $\mathrm{D}$ & M & $\mathrm{C}$ & Otro & Habilitada & No usada & Total \\
\hline $1-4$ & Juan & Mamani & 4 & 1 & 2 & 1 & & 4 & & 4 \\
\hline $5,8,9,10$ & Fidel & Mamani & 4 & 1 & 1 & 1 & 1 & 2 & 2 & 4 \\
\hline 6,7 & Andres & Mamani & 2 & & & 1 & 1 & 1 & 1 & 2 \\
\hline $11-15$ & Tomás & Mamani & 5 & 1 & 2 & 2 & & 4 & 1 & 5 \\
\hline \multirow[t]{2}{*}{$16-22$} & Victor & Mamani & 7 & 3 & 2 & 1 & 1 & 7 & & 7 \\
\hline & & MAMANI & 22 & 6 & 7 & 6 & 3 & 18 & 4 & 22 \\
\hline $23-24$ & Leonardo & Condori & 2 & 1 & & 1 & & 2 & & 2 \\
\hline $25-28,35,42-44$ & Ambrosio & Condori & 8 & 2 & 1 & 2 & 3 & 7 & 1 & 8 \\
\hline $36,37,38$ & Juan B. & Condori & 3 & 1 & 1 & 1 & & 2 & 1 & 3 \\
\hline \multirow[t]{2}{*}{$\underline{39,40,41}$} & Francisco & Condori & 3 & 1 & 1 & 1 & & & 3 & 3 \\
\hline & & CONDORI & 16 & 5 & 3 & 5 & 3 & 11 & 5 & 16 \\
\hline $45-48,55,56$ & Juliano & Castro & 6 & 1 & 3 & & 2 & 5 & 1 & 6 \\
\hline $51,52,53$ & Faustino & Castro & 3 & 1 & 1 & 1 & & 3 & & 3 \\
\hline 54,61 & Isidro & Castro & 2 & & 1 & 1 & & 2 & & 2 \\
\hline $57,58,59$ & Domingo & Castro & 3 & 1 & 1 & 1 & & 3 & & 3 \\
\hline $62,64,65$ & Antonio & Castro & 3 & & 1 & 1 & 1 & 3 & & 3 \\
\hline $63,66 \mathrm{~A}-68,109$ & Agustin & Castro & 6 & 1 & 2 & 1 & 2 & 5 & 1 & 6 \\
\hline 69,71 & Julio & Castro & 3 & 1 & 1 & 1 & & 3 & & 3 \\
\hline 72,75 & Leonardo R. & Castro & 4 & & 2 & 1 & 1 & 2 & 2 & 4 \\
\hline $76,77,78$ & Andres & Castro & 3 & 1 & 1 & 1 & & 3 & & 3 \\
\hline $84-86,100$ & Juan S. & Castro & 3 & 1 & 1 & & 1 & 2 & 1 & 3 \\
\hline $60,82,83$ & Sefarino & Castro & 3 & 1 & 1 & 1 & & 3 & & 3 \\
\hline $79,80,81$ & Claudio & Castro & 4 & 1 & 2 & 1 & & 4 & & 4 \\
\hline $87,101-103,112$ & Marcos & Castro & 5 & 1 & 3 & 1 & & 4 & 1 & 5 \\
\hline $88,89,90$ & Clemente & Castro & 4 & 1 & 1 & 2 & & 3 & 1 & 4 \\
\hline $91,92,95,108$ & Paulino & Castro & 4 & 1 & 2 & 1 & & 4 & & 4 \\
\hline 93,94 & Felipe & Castro & 2 & & & 1 & 1 & 2 & & 2 \\
\hline 96,97 & Pedro & Castro & 2 & & 1 & 1 & & 2 & & 2 \\
\hline 98 & Juana & Castro & 1 & & & & 1 & 1 & & 1 \\
\hline 99,107 & Juan & Castro & 2 & & 1 & 1 & & 2 & & 2 \\
\hline 104-106, 111 & Carlos & Castro & 4 & 1 & 1 & 1 & 1 & 3 & 1 & 4 \\
\hline 110 & Angel & Castro & 1 & & 1 & & & & 1 & 1 \\
\hline \multirow[t]{4}{*}{$\underline{113,114,115}$} & Natividad & Castro & 3 & 1 & 1 & 1 & 1 & 3 & & 3 \\
\hline & & CASTRO & 71 & 13 & 28 & 19 & 11 & 62 & 9 & 71 \\
\hline & & MAMANI & 22 & 6 & 7 & 6 & 3 & 18 & 4 & 22 \\
\hline & & CONDORI & 16 & 5 & 3 & 5 & 3 & 11 & 5 & 16 \\
\hline $29-34$ & & ESCUELA & 6 & 1 & 2 & 1 & 2 & 6 & & 6 \\
\hline \multirow[t]{2}{*}{$\underline{49-50}$} & & IGLESIA & 2 & & & & 2 & 2 & & 2 \\
\hline & & TOTAL & 117 & 25 & 40 & 31 & 21 & 99 & 18 & 117 \\
\hline
\end{tabular}

$\mathrm{A}=$ adobe [con + : casa abandonada $]$

$\mathrm{P}=$ piedra

$1=$ techo de un agua

$2=$ techo de dos aguas

$4=$ techo de cuatro aguas

$\mathrm{C}=$ cocina

$\mathrm{D}=$ dormitorio

$\mathrm{M}=$ despensa

Ventana: 1 una ventana, 1/T vent. tapada, $1 / \mathrm{V}$ con vidrio,

$1 / \mathrm{M}$ con madera

Vent $=$ ventilación 


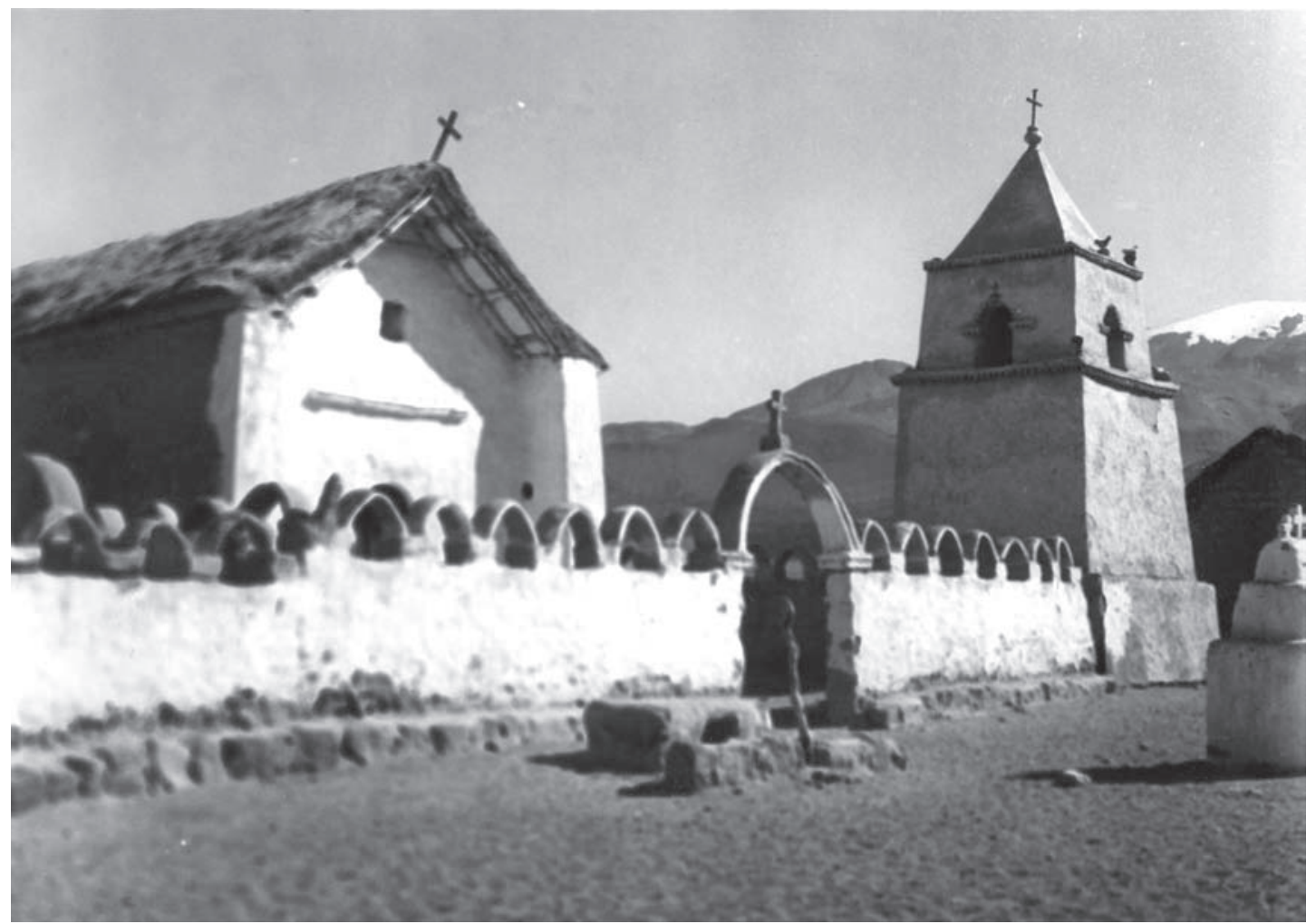

Figura 3. Iglesia de San Santiago, Santo Patrono de Enquelga, construida de adobes y piedras.

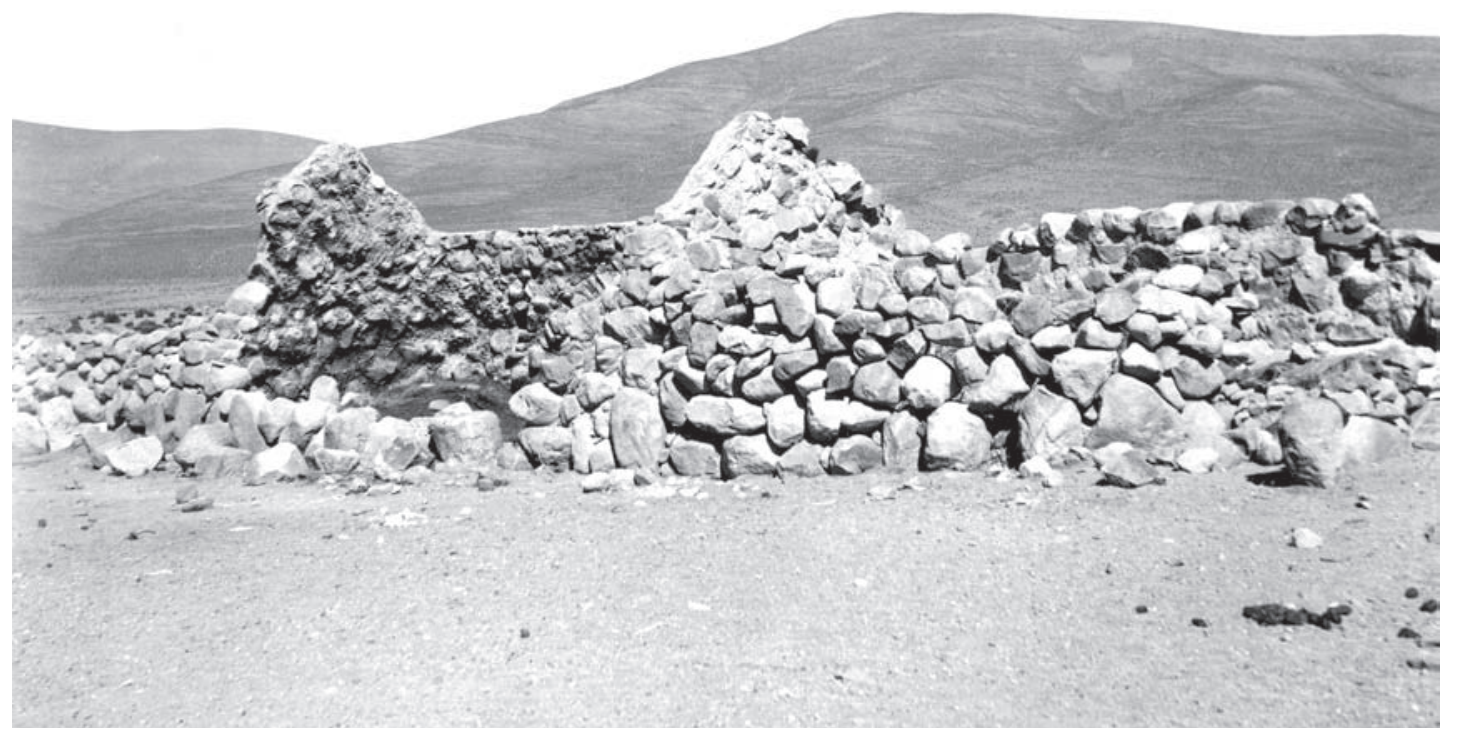

Figura 4. Resto de una casa de piedras ( $\left.\mathrm{N}^{\mathrm{o}} 111\right)$. 


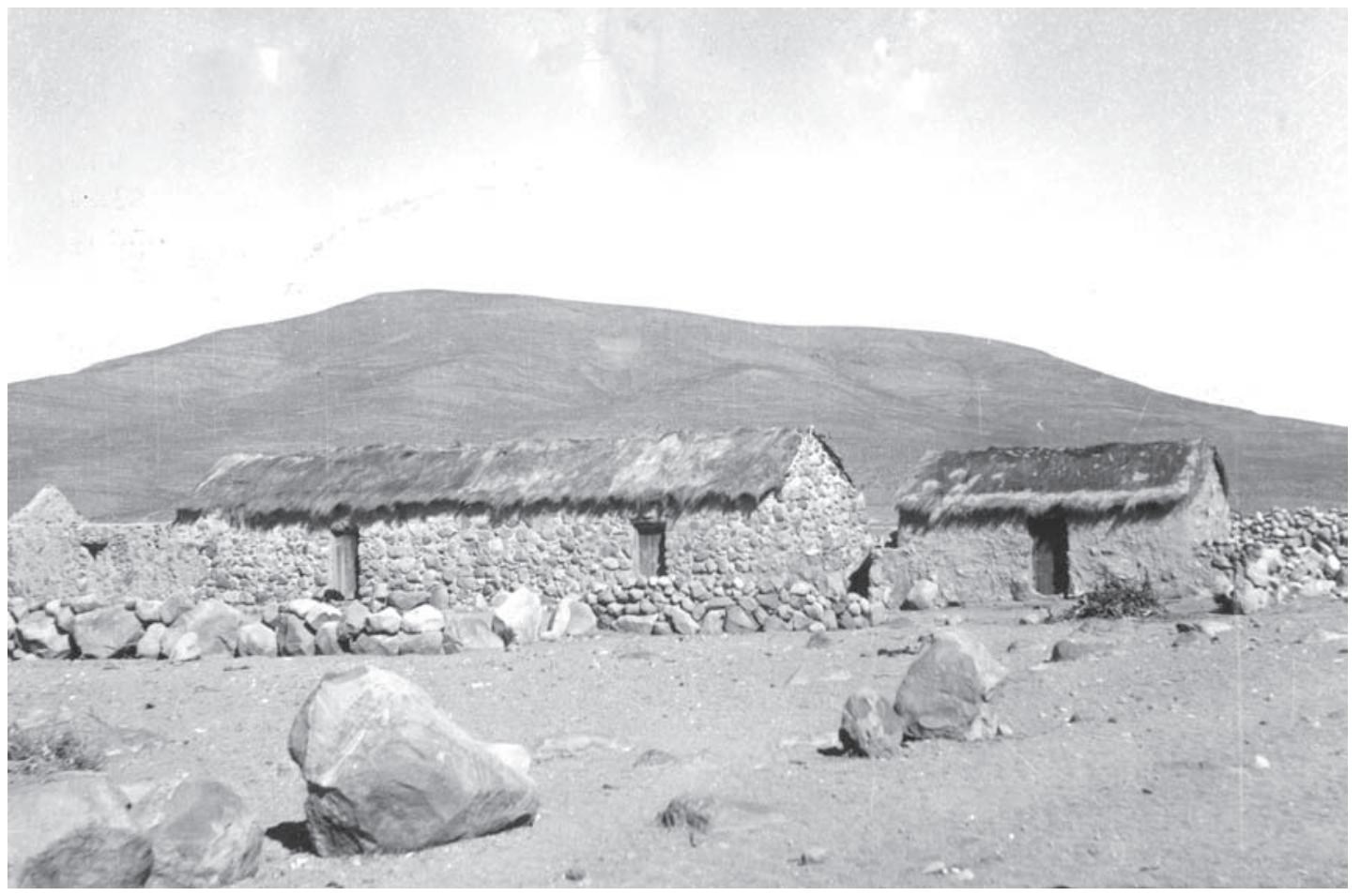

Figura 5. Casas de piedras ( $\left.\mathrm{N}^{\text {os. }} 112-115\right)$.

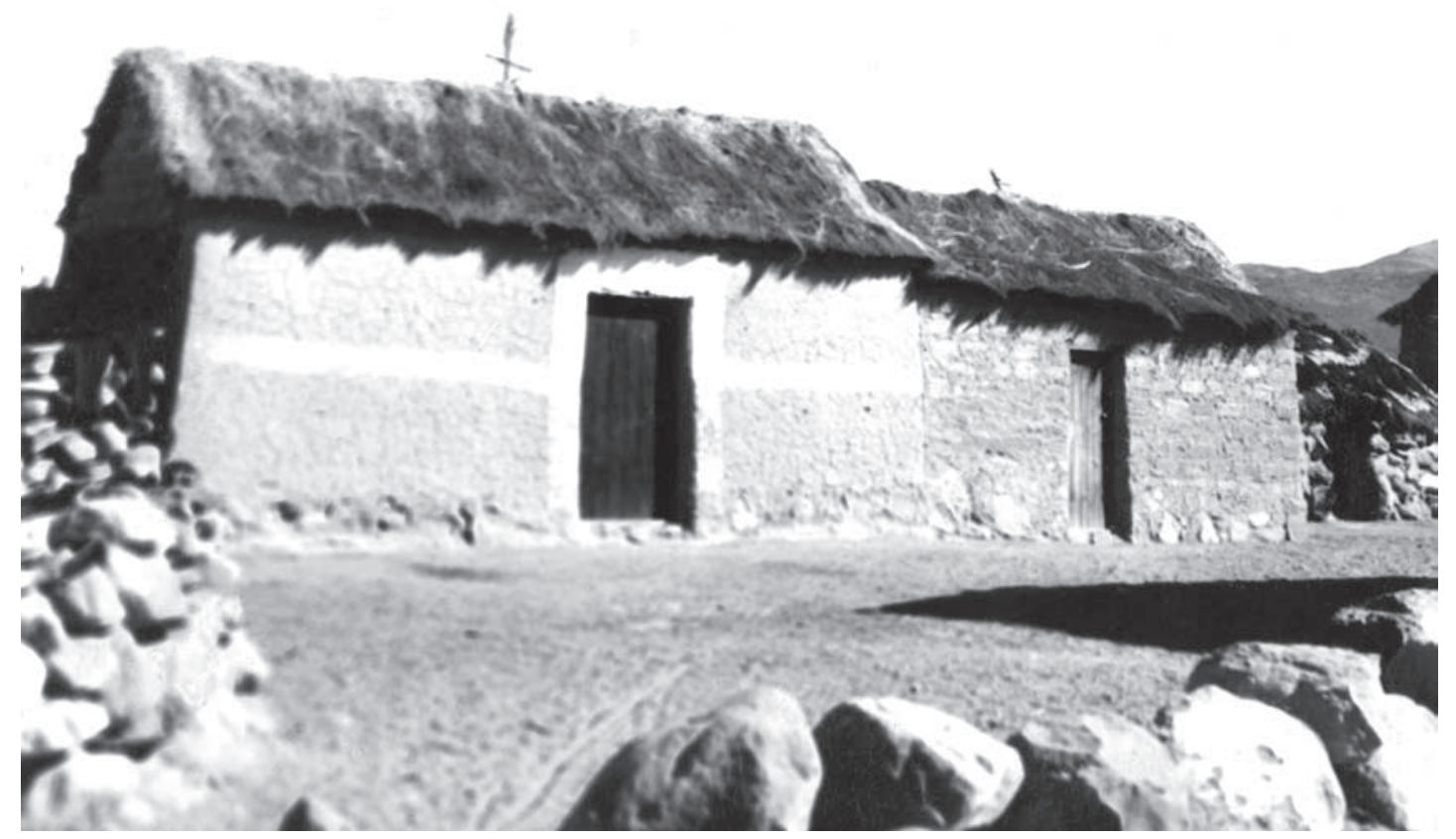

Figura 6. Casas de adobes con revoque (N $\left.{ }^{\text {os. }} 102,103\right)$. 


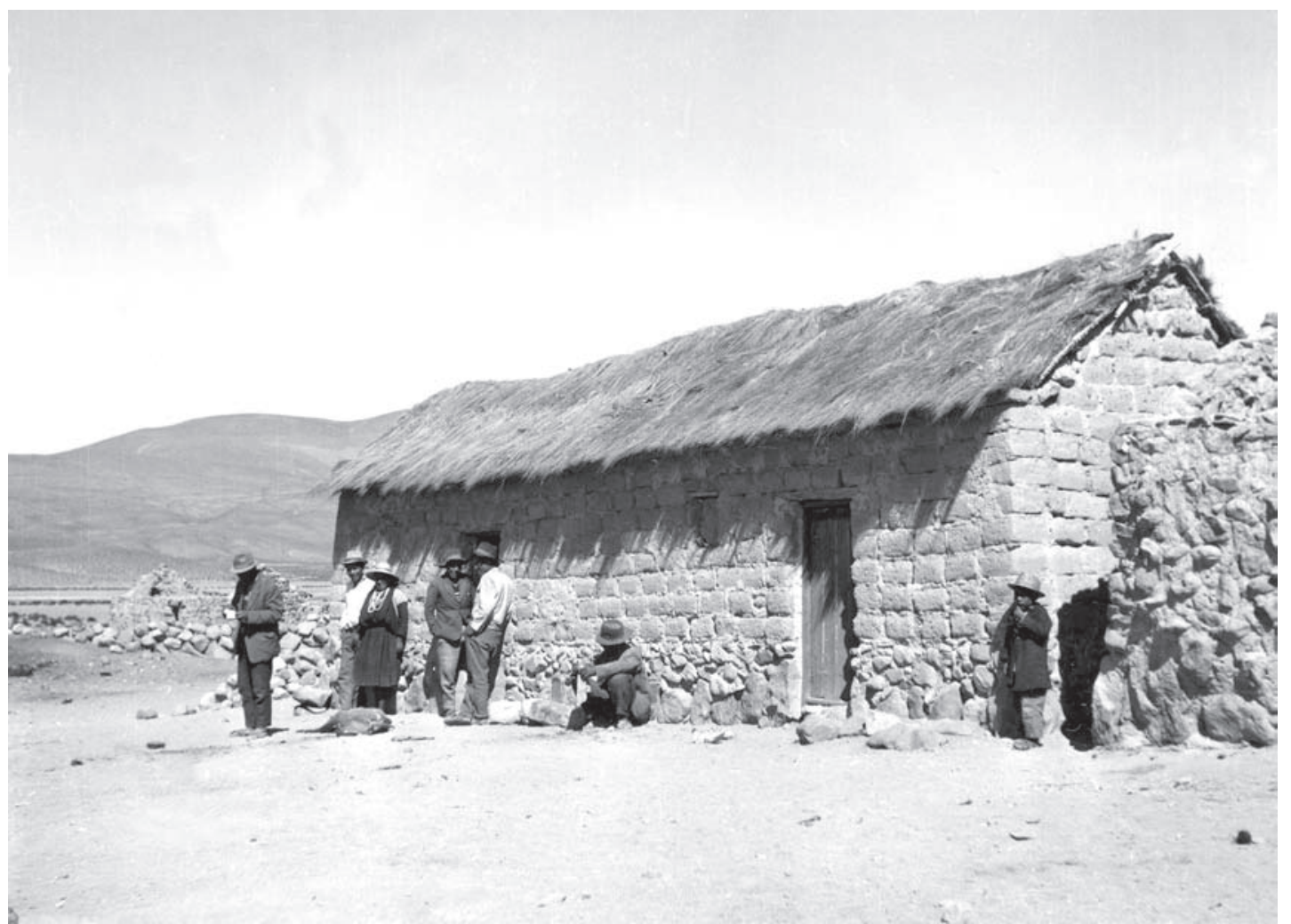

Figura 7. Casa con muros de piedras con adobes ( $\left.\mathrm{N}^{\text {os. }} 80,81\right)$.

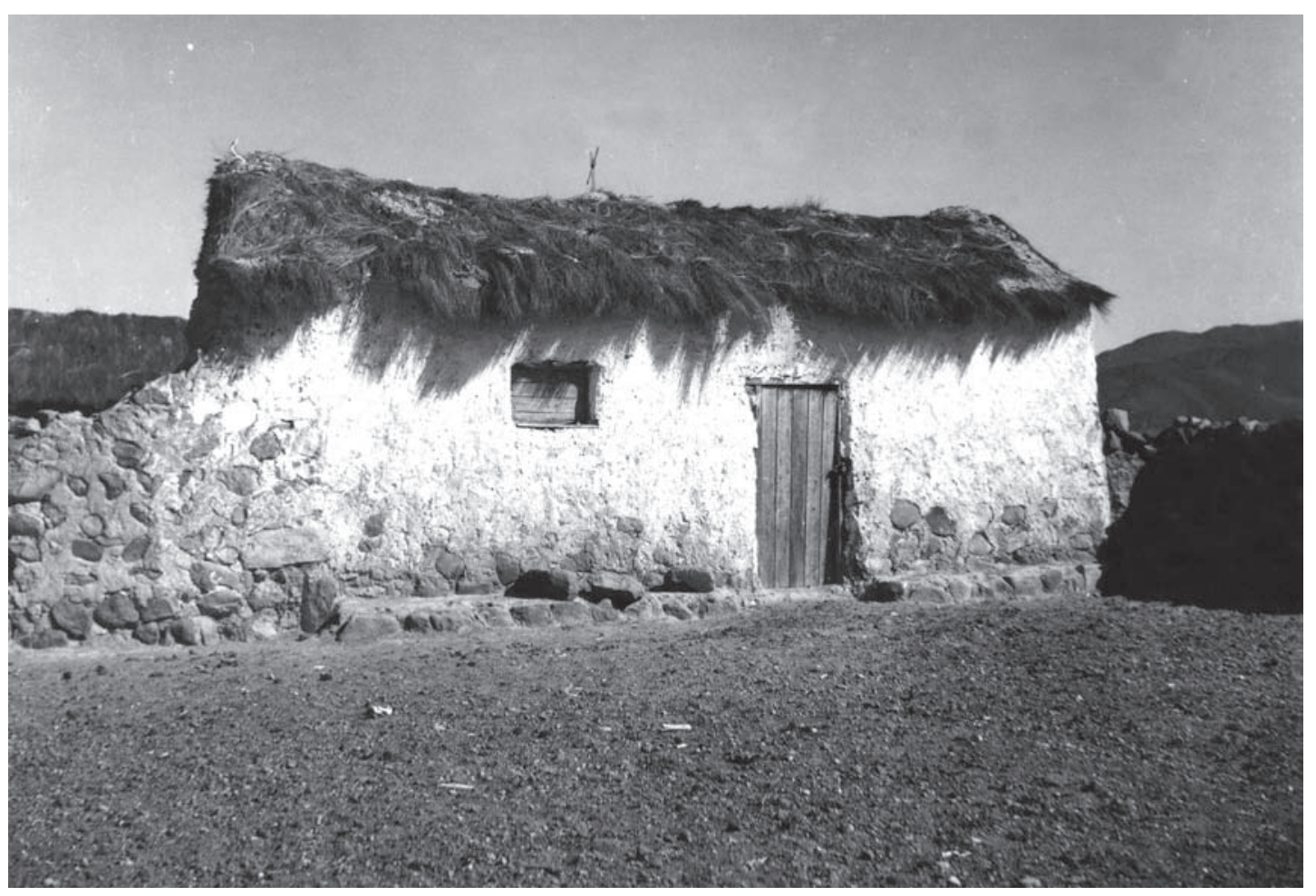

Figura 8. Casa de adobes con piedras $\left(\mathrm{N}^{\circ} 36\right)$. 


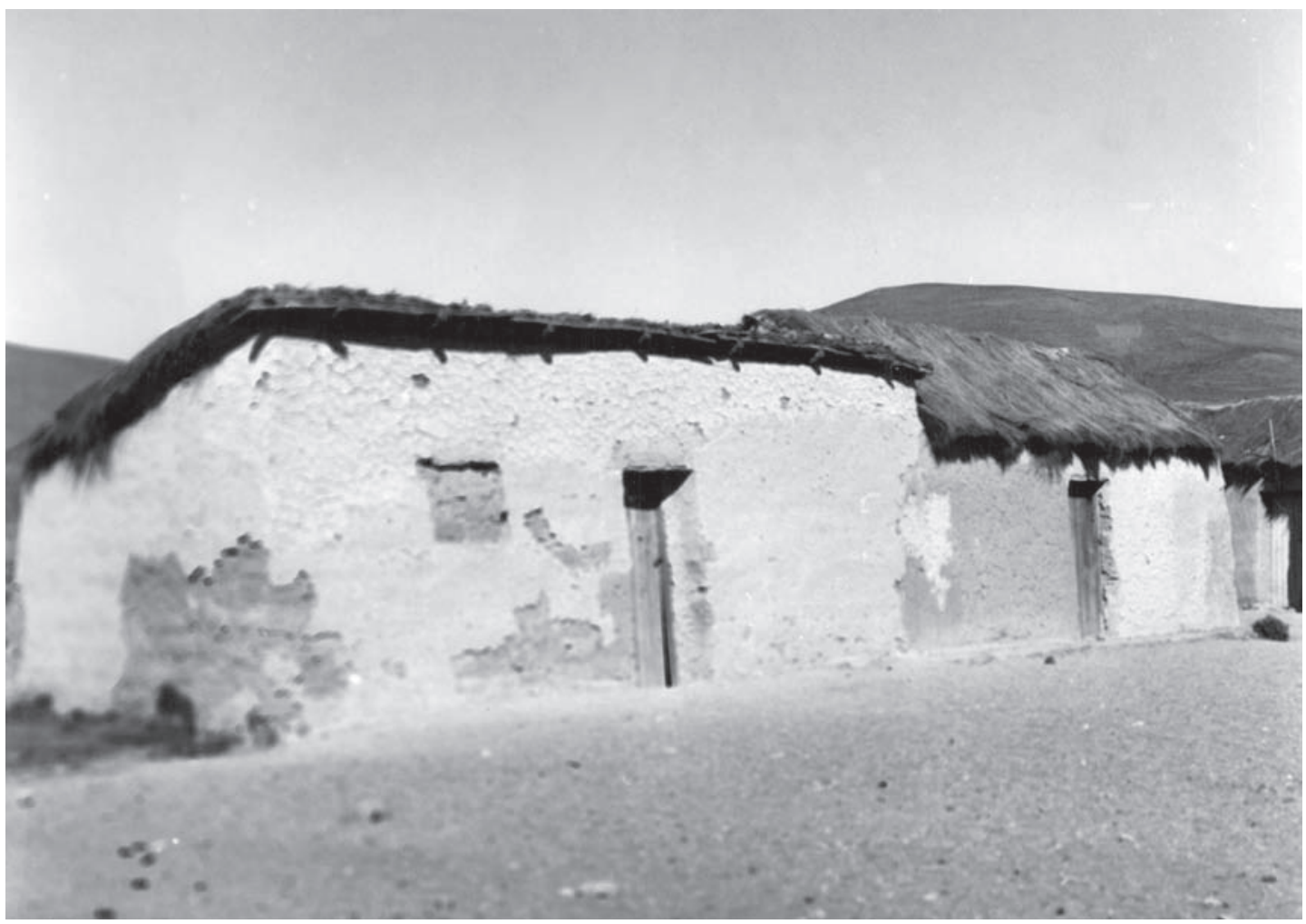

Figura 9. El techo de un agua $\left(\mathrm{N}^{\circ} 45\right)$.

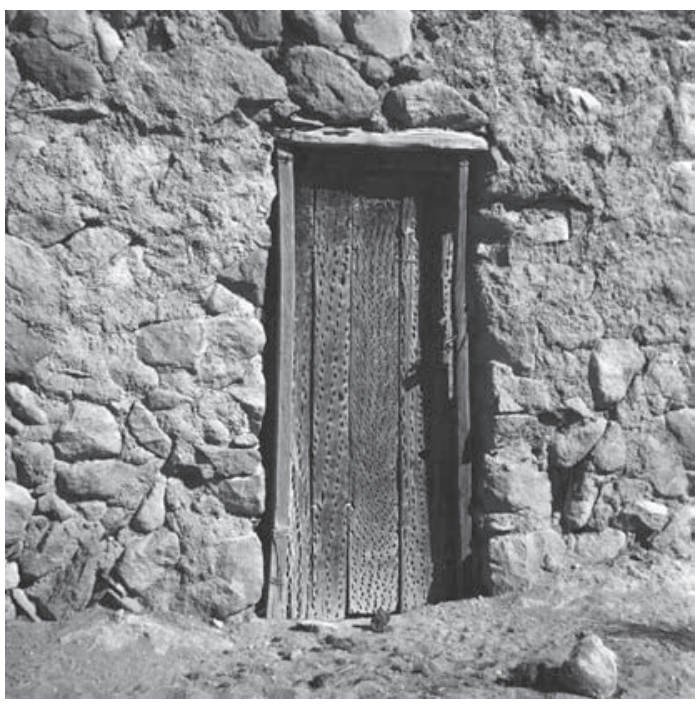

Figura 10. Puerta de madera (cacto cardón) ( $\left.\mathrm{N}^{\circ} 108\right)$.

barro, dejando el vidrio hacia afuera (Figura 12). Dicen que en las casas donde hay ventanas hace en la noche mucho frío. En todas las casas hemos constatado solamente 22 ventanas, sin contar las ventanillas chiquitas de ventilación que existen en varias casas, especialmente en las cocinas.
Comparando los tamaños de las casas el promedio del largo de ellas es entre 3,6 y 9,7 metros. Como ancho mínimo fue constatada la medida de 2,2 metros y como máximo 4 metros. Esto da un promedio de 3 metros, aproximadamente. En la altura hemos encontrado diferencias de 2 metros. La altura del techo fluctúa entre 0,9 y 1,3 metros (Tabla 1).

Según su uso o destinación podemos distinguir tres tipos fundamentales de casas, algunos especiales y algunos tipos combinados (Tabla 1). La mayoría de las familias (31 familias en Enquelga) tiene un conjunto de 3 casas. Una sirve como cocina, otra como dormitorio y la tercera como despensa (Figuras 13 y 14). Nuestra investigación encontró 30 cocinas, 26 dormitorios y 38 despensas, casas utilizadas estrictamente para una de estas tres funciones mencionadas. Podemos entonces hablar sobre 26 conjuntos completos. Algunos dueños de familias más grandes, o con bastante espacio o con un poco más de bienes tienen el conjunto mencionado con una despensa adicional. Otros, los más pobres, menos trabajadores, o con menos espacio tienen casas para el uso combinado. Así hemos constatado 7 dormitorios que sirven también como 


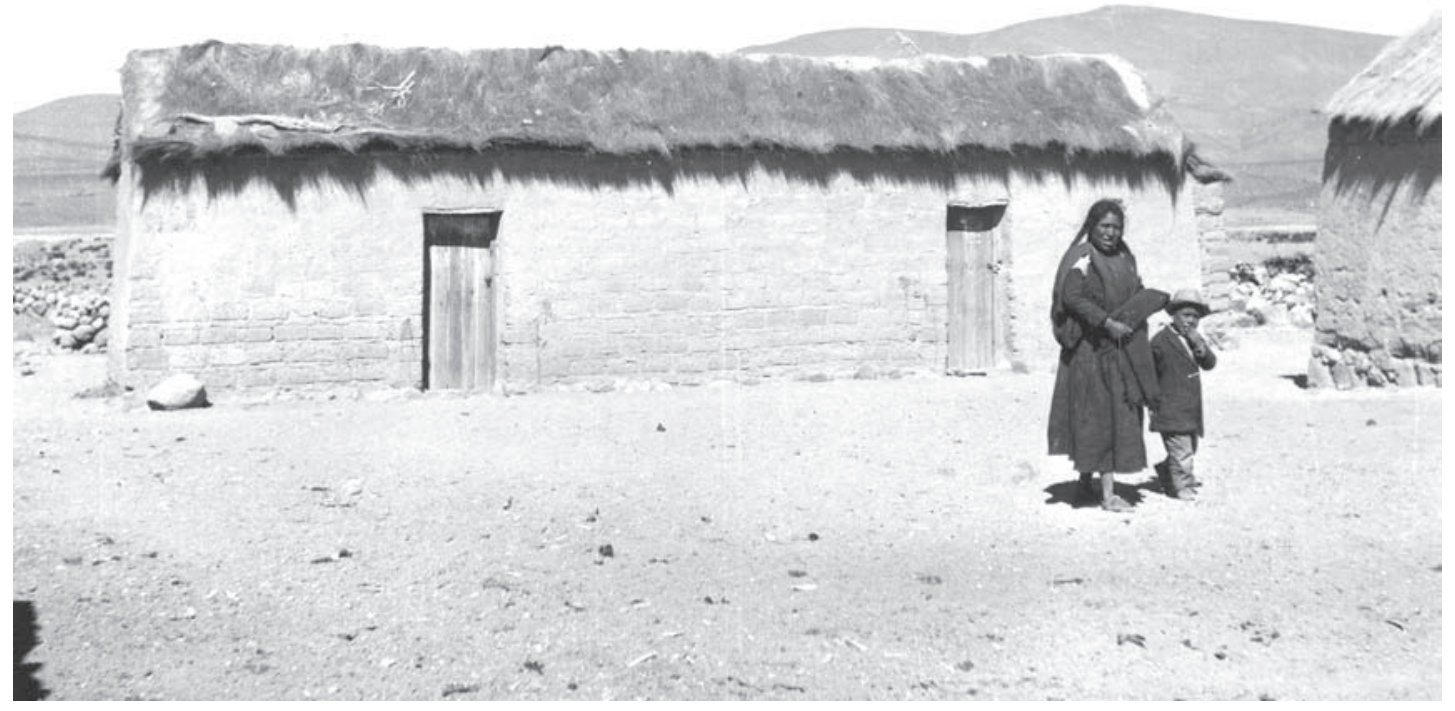

Figura 11. Casa de adobes sin ventanas ( $\left.\mathrm{N}^{\text {os. }} 82,83\right)$.

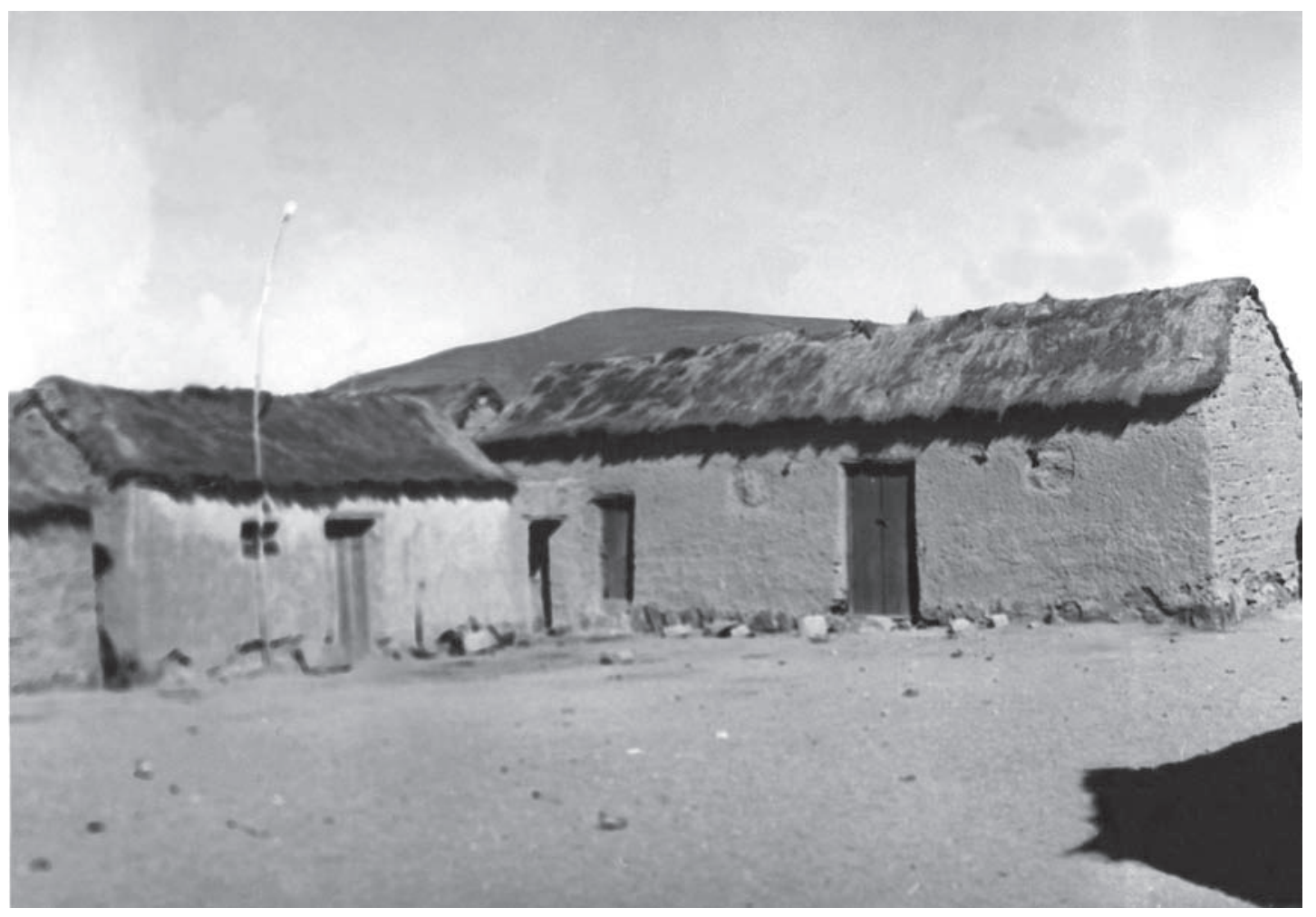

Figura 12. Casa con ventanas tapadas ( $\left.\mathrm{N}^{\mathrm{o}} 14\right)$. 


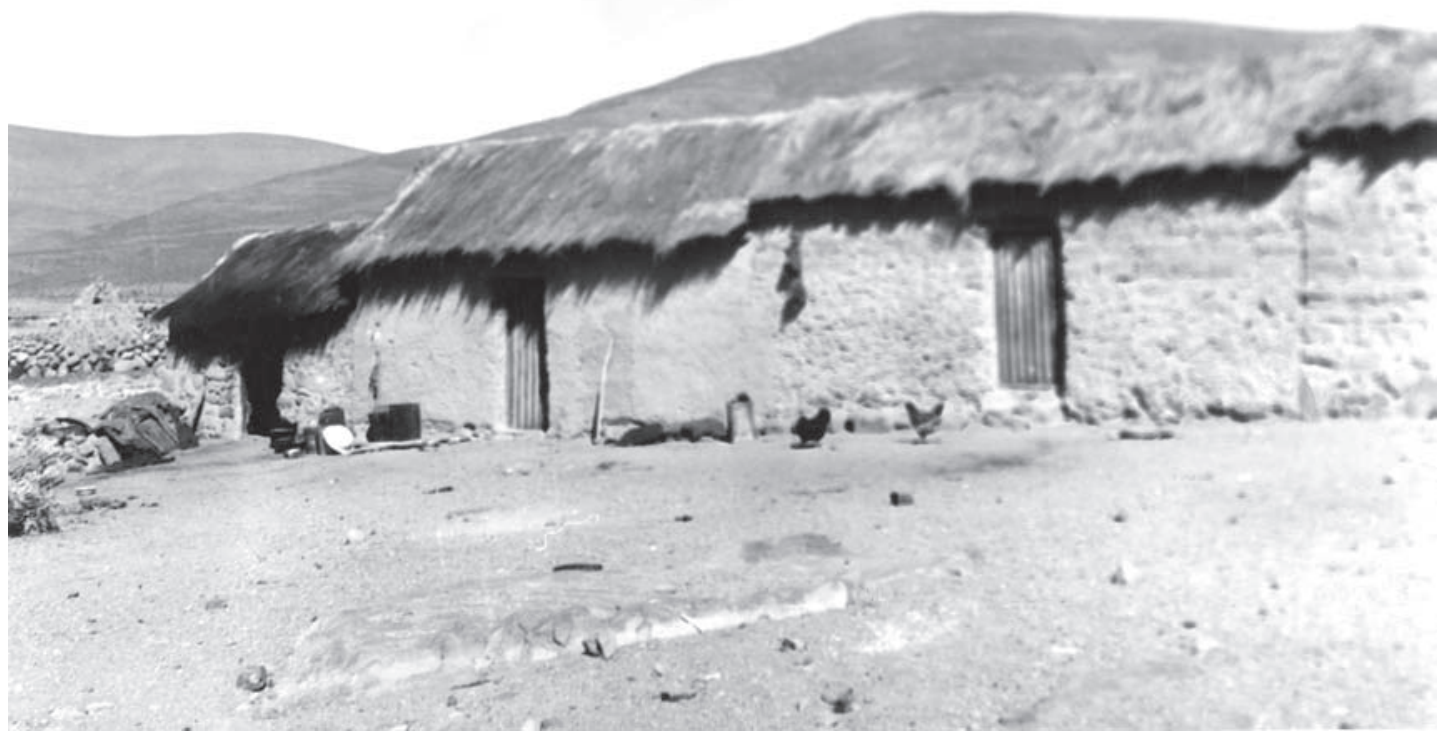

Figura 13. Despensa y dormitorios de adobes, cocina de piedras ( $\left.\mathrm{N}^{\text {os. }} \mathbf{5 7}, \mathbf{5 8}, 59\right)$.

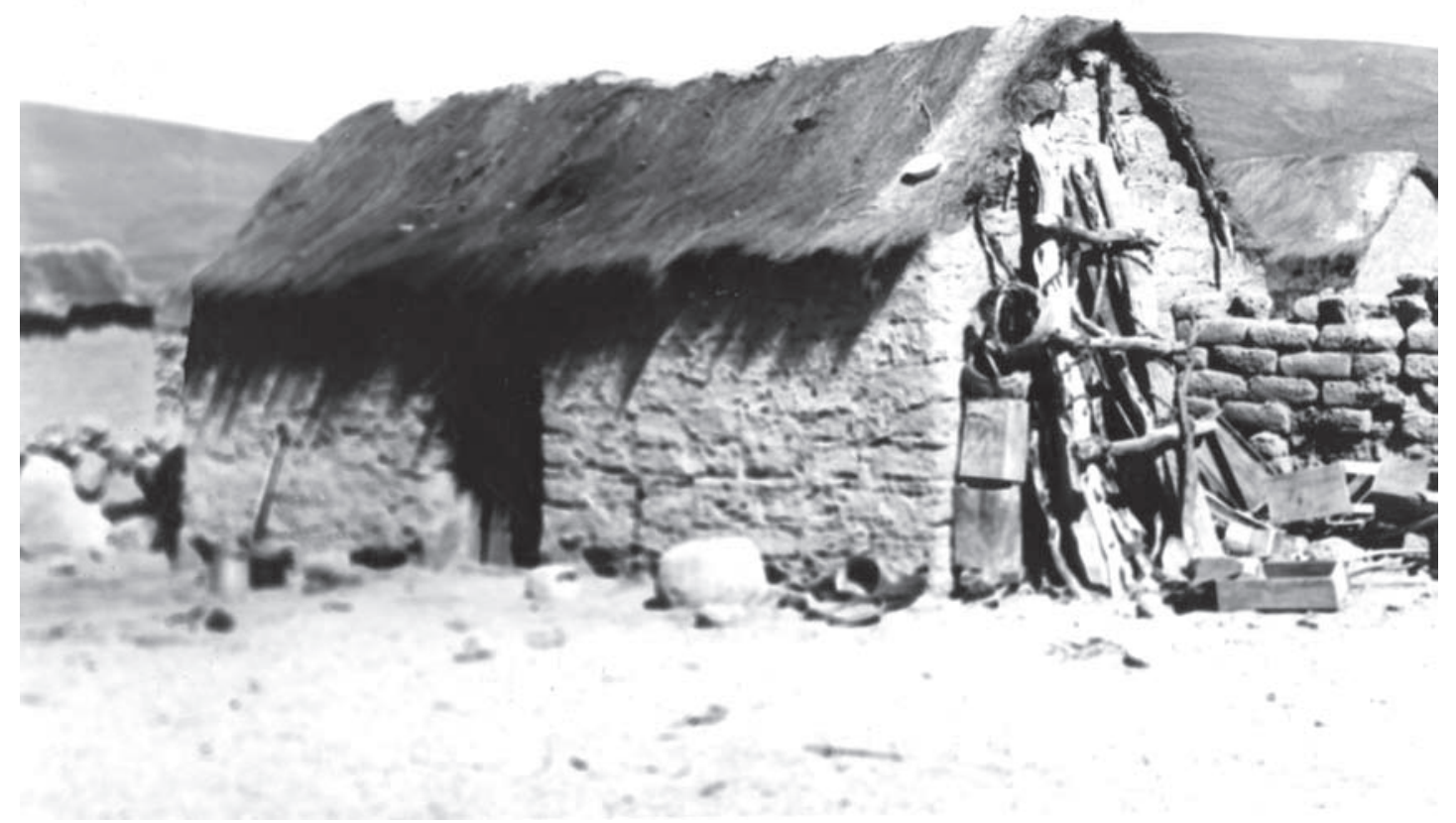

Figura 14. Una cocina típica $\left(\mathrm{N}^{\circ} 71\right)$. 
despensas; un dormitorio que sirve también como cocina y una despensa especial que sirve también como pequeño negocio (de Ambrosio Condori). Dos familias tienen casas especiales para recibir visitas de otros lugares y un hombre se construyó una casa especial para fiestas, antes ya mencionada (Tabla 1). La función de las otras casas no tuvimos posibilidad de identificar.

La construcción de la casa común es muy simple. El dueño-constructor la hace él mismo con ayuda de uno o dos amigos. Cuando no tiene experiencia, busca a un ayudante que la tenga. Primero hay que tener preparados bastantes adobes (Figura 15), hechos con ayuda de un molde simple de tablas chicas. La ayuda de amigos o vecinos es pagada o se devuelve en trabajo cuando el ayudante lo necesite, según acuerdo entre ellos. En el caso de pagarla no es necesario de pagarla en plata. Los indios prefieren recibir el valor de su trabajo en papas, carne u otras mercaderías.

Primero excavan una zanja poco profunda para construir los fundamentos de piedra, de una altura de 25-60 centímetros según la voluntad del dueño. Sobre estos fundamentos construyen los muros (Figura 16), dejando espacio para la puerta o también para las ventanas. El espesor de los muros es entre 35 y 40 centímetros; abajo un poco más ancho y arriba más estrecho y ligeramente inclinado hacia dentro.

Terminados los muros de la casa los dejan secar durante una semana aproximadamente y se dedican a trabajos preparatorios para la construcción del techo. Primero hay que tener una cantidad bastante grande de paja brava llamada en el aymara ichu (Stipa ichu), especie de paja bastante larga y dura que crece en grandes cantidades sobre las faldas de los montes. Se utiliza la paja cuando está completamente seca y la sacan de manera cuidadosa para no romperla. La arrancan con raíces, en puñados, para mantener a los mechones bien juntos. Luego la ligan en atados de un diámetro más o menos de 50 centímetros. Los atados se amarran con sogas de lana y los transportan sobre el lomo de las mulas o llamas.

En el mismo lugar donde quieren construir la casa dividen la paja ichu en dos partes. La más grande la dejan al lado para uso posterior y la más chica la prepararan para la fabricación de una especie de calamina, llamada p'ira (Figura 17). De toda esta paja hay que cortar la parte inferior con raíces, porque para la fabricación de la p'ira necesitan paja suelta. Este proceso de cortar las raíces es trabajo de las mujeres. El hombre clava a la tierra una estaca de madera de unos 50-60 centímetros, dejando afuera de la tierra una parte de 15 centímetros. A esta estaca amarra la mujer una hoz de fierro, dentada, de modo, que el mango está amarrado a la estaca, con el arco de la hoz hacia la mujer sentada, con la punta hacia arriba y con el corte [filo] hacia delante.

La mujer se sienta con las piernas cruzadas a la tierra, detrás de la hoz, con su cara hacia el arco, con el montón de la paja ichu a su lado derecho. Con ambas manos toma puñados de paja y con un movimiento de arriba-abajo sobre el corte [filo] de la hoz se corta la parte de la paja con raíces para mantener la paja suelta y limpia, la que pone aparte.

Los hombres mientras tanto cavan en el terreno un hoyo aproximadamente de un metro de diámetro y por una cuneta traen agua del arroyo cercano o de un canal de riego más cercano. En el hoyo preparan después, utilizando sus manos y sus piernas, una especie de barro poco consistente y fino de tierra, sin piedritas muy grandes. Esto es trabajo del hombre, al que ayudan las mujeres y los niños (traen agua y tierra fina). Este proceso llaman ñekke jiruñani -mezclar barro (Figura 18).

Después todos barren con las escobillas de la paja mencionada, un lugar cercano al edificio futuro, bien plano y bastante grande. Con una soga de lana mide el constructor la superficie (el tamaño) del techo futuro, midiendo primero el largo y después el ancho sobre un hastial de la casa futura. La superficie así obtenida después la marca con rayas en el espacio limpiado.

Sobre este espacio medido y marcado echan la paja suelta preparada, de manera que cae desde arriba sobre la superficie. La paja tiene que caer cruzada, en varias direcciones, para formar una capa delgada y regular sobre toda la superficie del terreno marcado. Teniendo la capa lista, arreglan los bordes de la capa con un palo, hacia dentro. Toda esta superficie después la pisan con las piernas desnudas, bajando así el grosor de la paja ichu.

Después el ayudante del constructor trae en una lata vacía de aceite el barro preparado desde el hoyo mencionado. El barro es de una consistencia especial, no muy consistente y no muy espeso, bien amasado y el constructor lo extiende con sus manos cuidadosamente en una capa regular sobre la paja tendida. Cuando la capa del barro se seca un poco, el 


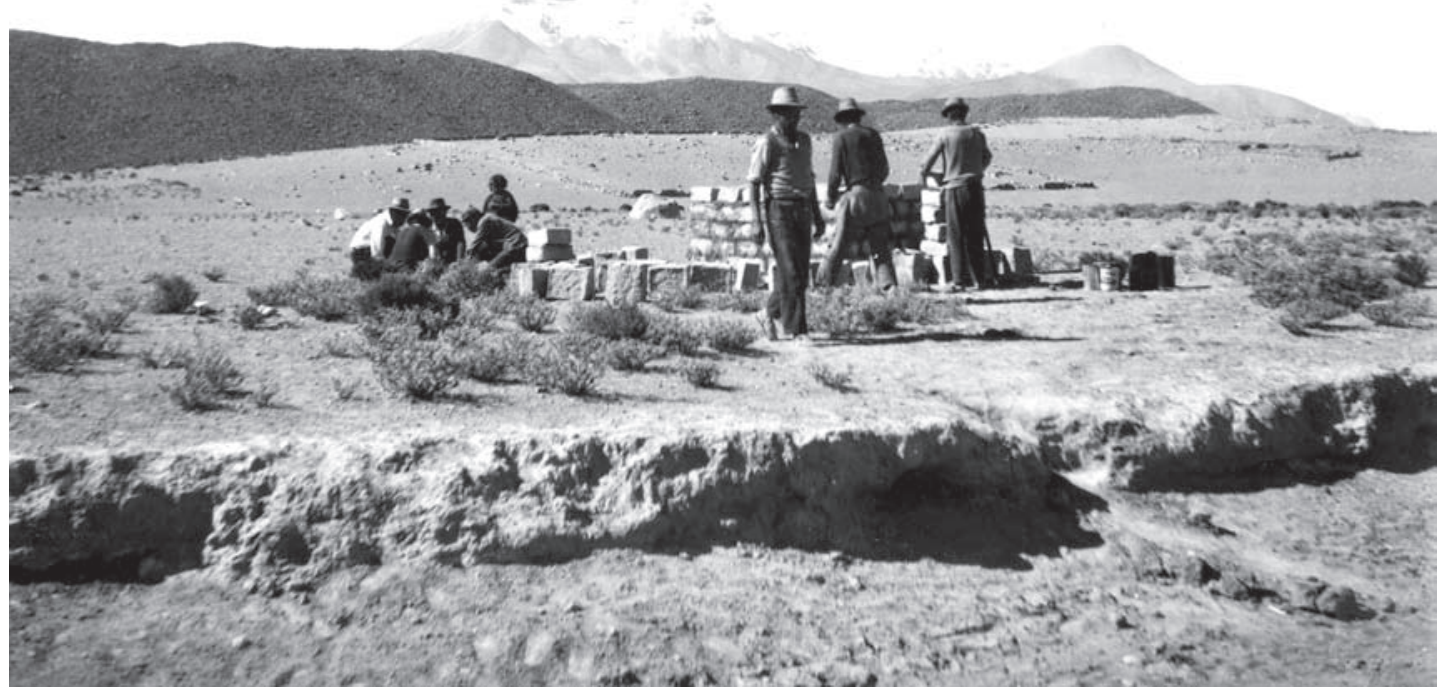

Figura 15. Una casa nueva en construcción.

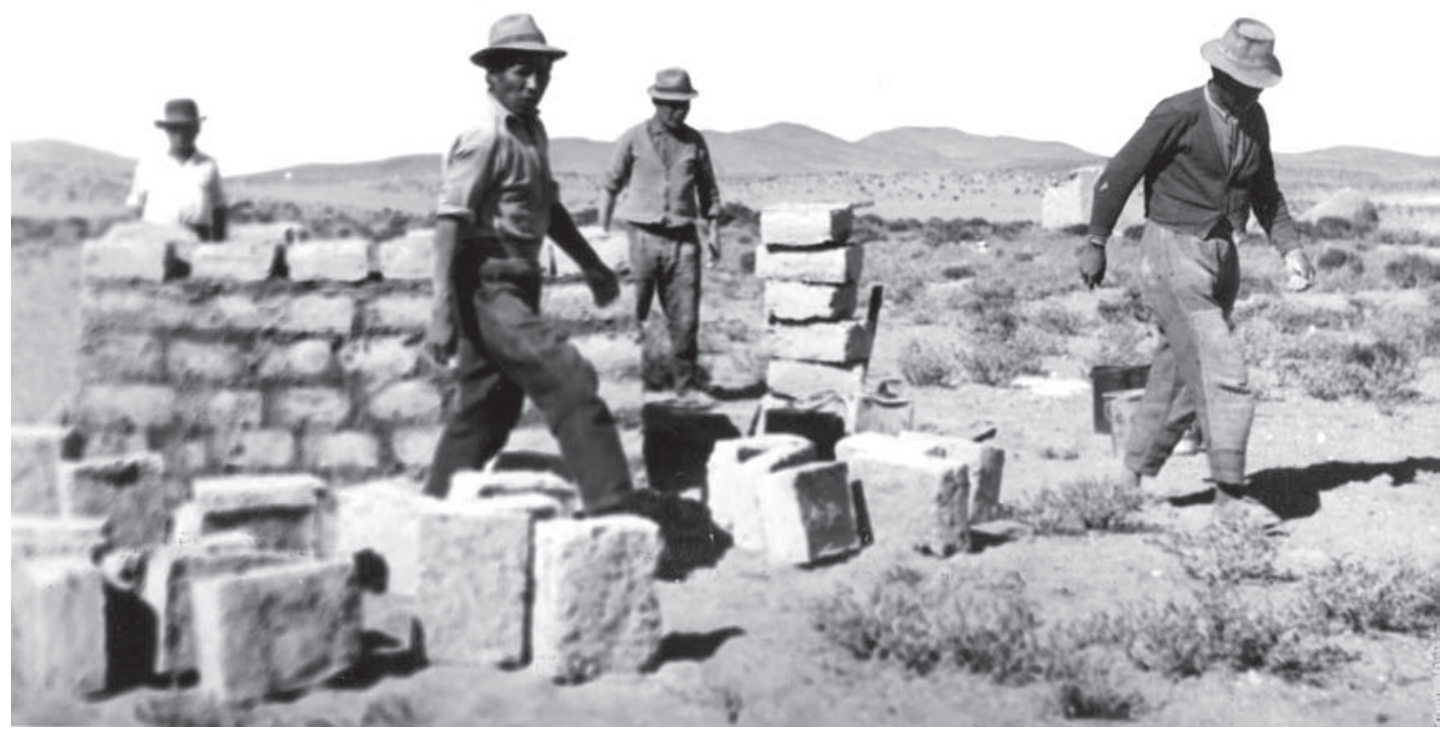

Figura 16. Construcción de adobes. 


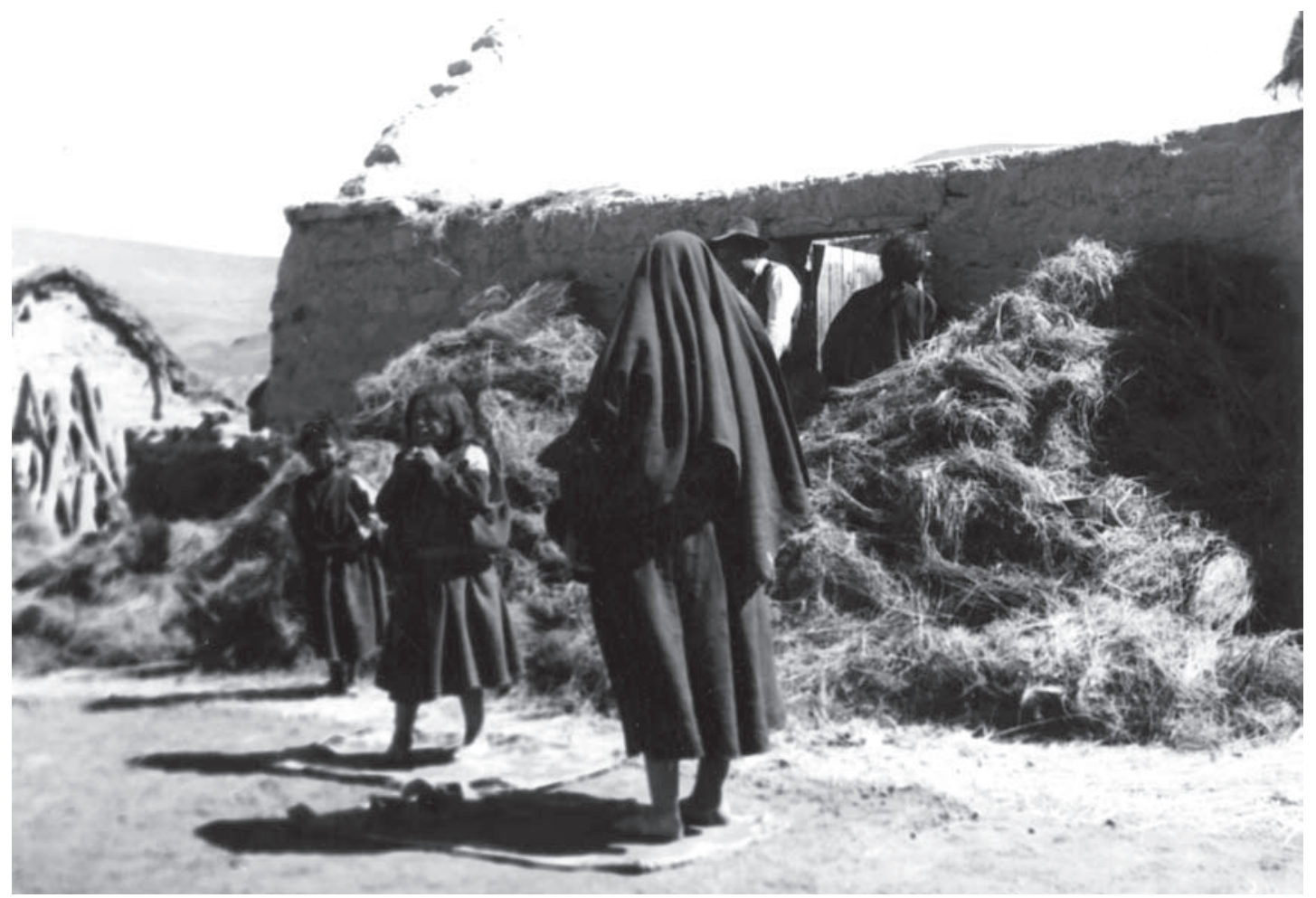

Figura 17. Fabricación de la p’ira.

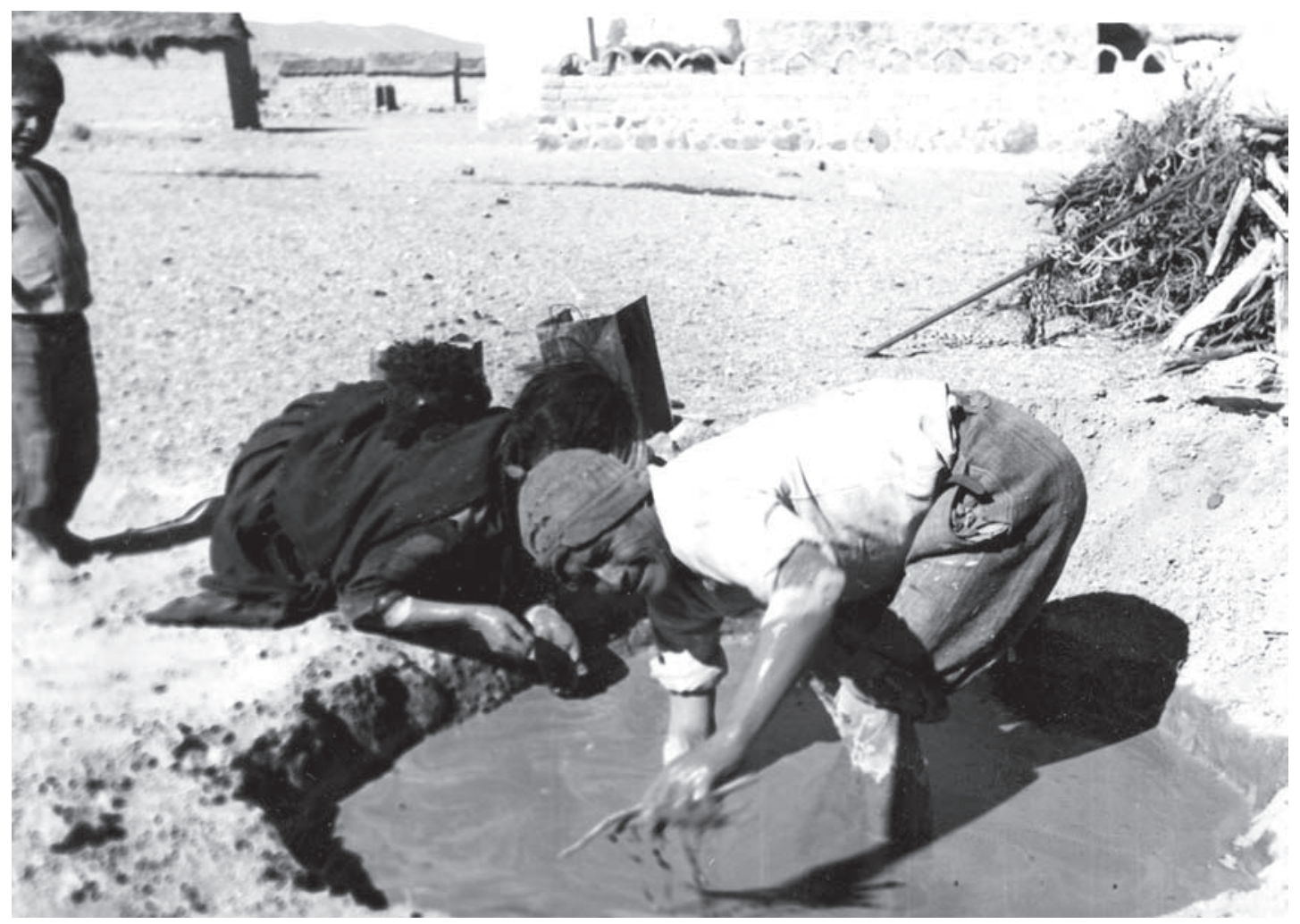

Figura 18. Preparación del barro. 
fabricante tiene que buscar algunos ayudantes; cada uno de ellos tiene que llegar con un saco llamado costal, de lana, vacío. Tiende el saco sobre el barro y lo pisotea con pasos cortos, para apisonar bien toda la superficie cubierta con el saco (Figura 19). Después levanta el saco, lo tiende al lado y pisotea otra vez. Así pisotea sucesivamente toda la superficie de paja con barro, dejando sobre el barro el dibujo de la estructura de los sacos.

Entretanto el grupo de tres o cuatro hombres expertos en el interior de la casa futura eligen maderas para la armadura del techo. Tienen que corresponder siempre en pares en el largo y en su grosor (en el caso observado había nueve parejas). Estas vigas las arreglan, desbastan y las hacen más rectas con hachas; después las amarran en las puntas superiores con correhuelas de cuero crudo de llama, mas o menos de 1,5 cm de ancho, remojadas en agua $\mathrm{y}$ estos cabrios en forma de unas $\mathrm{V}$ puestos al revés ponen en orden juntos en un lado de la casa.

Afuera de la casa mientras tanto dividen la superficie de la $p$ 'ira con ayuda de una soga, primero en el sentido longitudinal en dos mitades y después en sentido travesero en diez fajas o mejor dicho en veinte fajas en las dos unidades [mitades]. Cada faja tiene aproximadamente 2,5 $\mathrm{m}$ de largo y unos 70 centímetros de ancho. Con cuchillos grandes después cortan toda la p'ira en fajas arriba mencionadas y las dejan en el suelo sin moverlas. Cortar las fajas es un trabajo sumamente difícil y pesado y cansa rápido, de modo que los cortadores deben cambiarse frecuentemente. Este trabajo es considerado como poco popular.

Cuando tienen las armaduras listas, llega el dueño de la casa con una botella de pusitunka (una especie de alcohol traído de contrabando de Bolivia; pusi en aymara significa cuatro, tunka significa diez; total quiere decir "cuarenta" grados de alcohol). Con esta bebida rocía las vigas murmurando un conjuro o una oración como bendición de las armaduras. Su mujer trae desde la cocina un poco de carbón de madera ardiente sobre un platillo metálico, lo mete bajo las armaduras preparadas y echa sobre el carbón un poco de resina como incienso. El humo lo dispersa con movimientos de sus manos bajo las armaduras para que alcance a todas. Cada uno de los ayudantes presentes obtiene para esta ocasión un puñadito de hojas de coca y un trago de alcohol. Una parte de estas hojas tiene que dispersarlas en la casa o puede también enterrarlas ligeramente en el suelo; de su porción de bebida tiene cada uno que echar unas gotas al suelo como ofrenda para la Pachamama, Madre Tierra, y después puede tomar el resto, murmurando algo como oración o bendición.

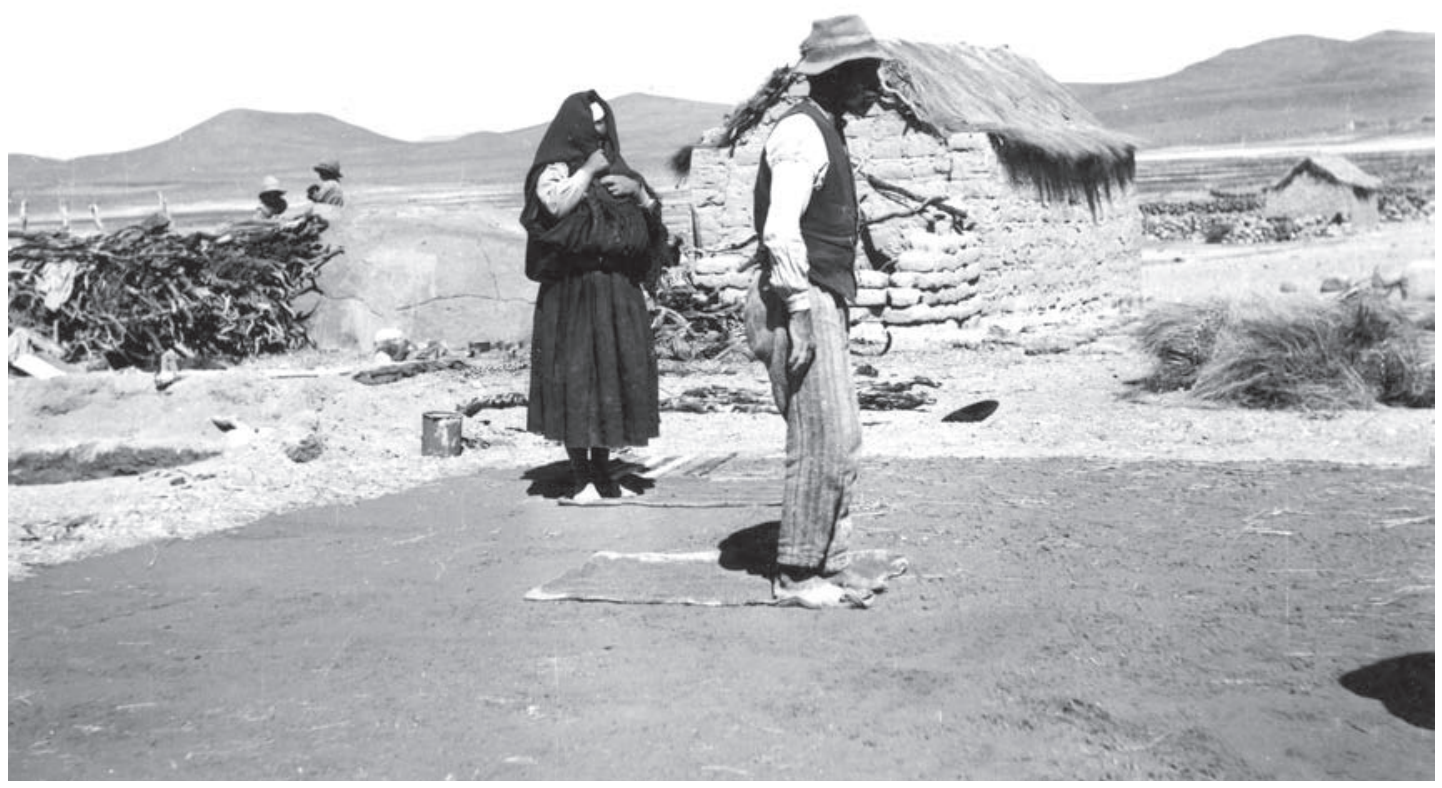

Figura 19. El matrimonio pisotea la p'ira. 
Después de terminar esta ceremonia levantan el primer par de vigas [hastiales] hasta su lugar medido y marcado sobre el borde del muro, donde se excavan para sus partes inferiores (en cada lado) un hoyuelo no muy profundo. Mientras tanto, juntan dos sogas de lana y las amarran a una altura de unos 60-70 centímetros de un hastial al otro, las extienden bien y el resto amarran abajo a una estaca. Estas sogas sirven como una construcción auxiliar para mantener las vigas parejas. Cuando las levantan, amarran una después de la otra a las dos sogas con pedazos de cuerdas (Figura 20).

Todos los trabajos principales, los trabajos difíciles y los que exigen una habilidad del cuerpo y fuerza los hacen los hombres. Las mujeres hacen trabajos auxiliares. Todos trabajan rápidamente, en un ritmo veloz, todos trabajan haciéndolo de mejor manera. Como ayudantes sirven aquí los amigos y parientes del constructor de la casa. En el caso observado participaron seis hombres y tres mujeres, incluido el constructor-dueño de la casa y su mujer.

Aun antes de terminar el levantamiento de las vigas dobles de las armaduras, empiezan los ayudantes a amarrar las maderas traveseras, al mismo tiempo en ambos lados de la construcción, empezando abajo, paralelamente con las murallas de la casa. Con esta duplicidad en el trabajo se forman de manera automática dos grupos de trabajadores, cada grupo en su lado del techo. Estos grupos hacen competencia entre ellos de modo que cada grupo pretende trabajar más rápido que el otro. Así continúa paso a paso el proceso de la construcción de la armadura del techo. Después de terminar la línea travesera primera más baja, continúan amarrando la segunda, más alta y finalmente la tercera. Todo se amarra con correhuelas de cuero remojado, las que se resecan más tarde y hacen la construcción más firme que los clavos de fierro (Figura 21). Como última etapa amarran el caballete del techo, que consiste regularmente de ligas (hastiales) más gruesas y fuertes que las maderas traveseras en común.

Para la construcción del techo utilizan dos especies de madera: $1^{\circ}$ los troncos de la queñua y $2^{\circ}$ los troncos rajados de la especie del cactus llamado cardón.

Sobre la construcción terminada de las armaduras cuelgan desde abajo dos objetos, especies

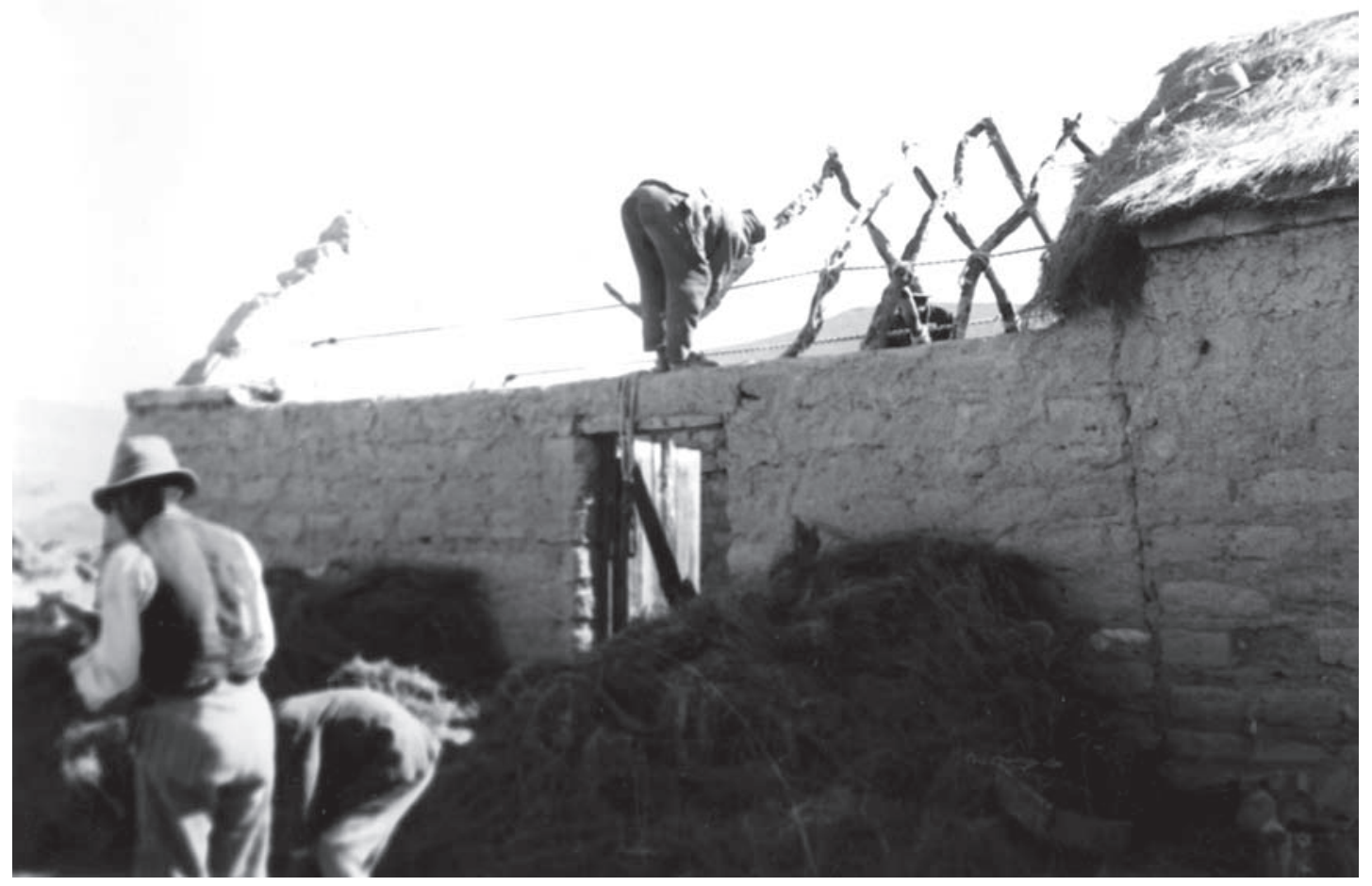

Figura 20. Construcción del techo. 


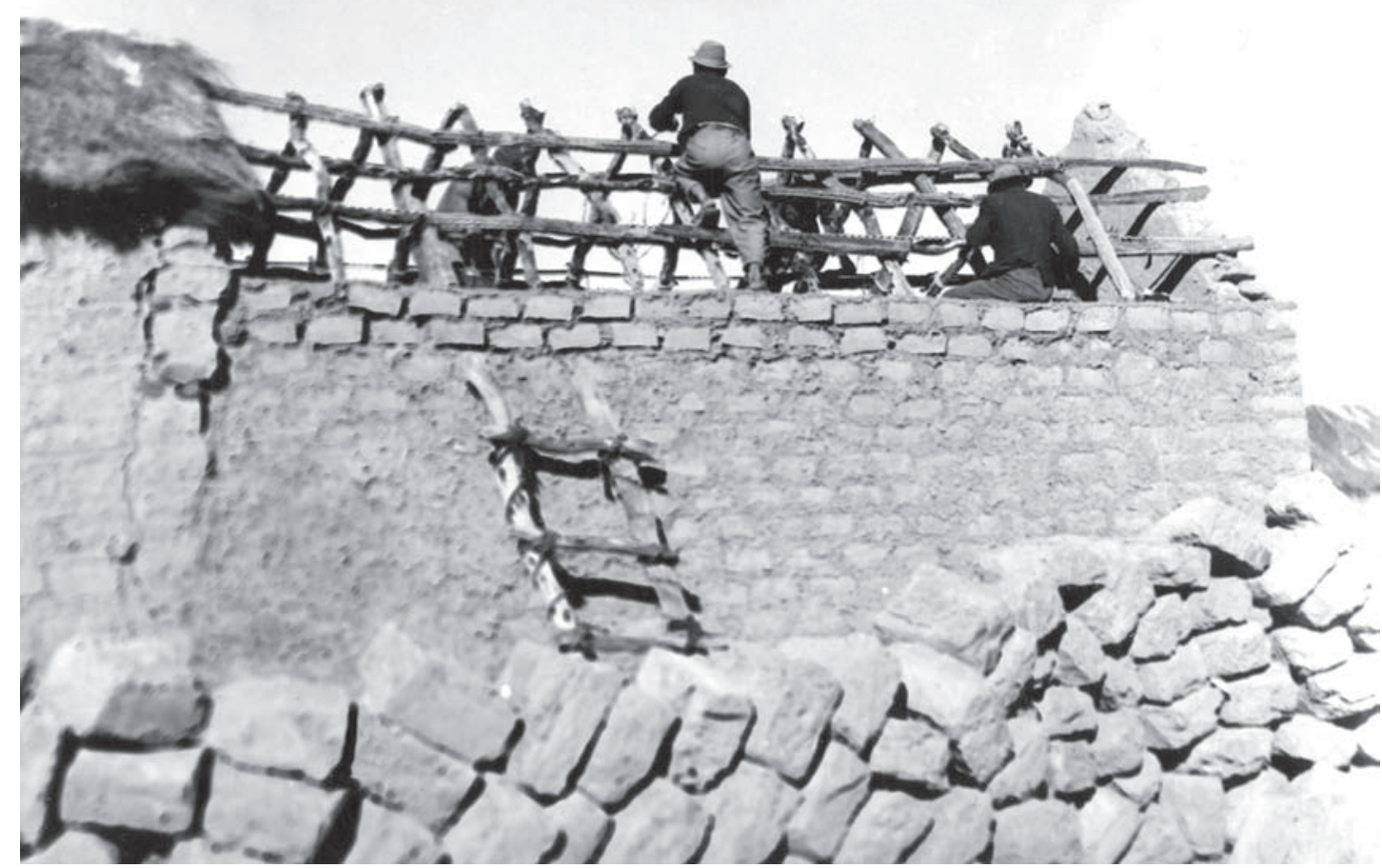

Figura 21. Construcción de las armaduras.

de amuletos, consistentes siempre de un cuadrito de lana de colores sobre una cruz pequeña de dos pedacitos de madera, bajo de la cual está pendiendo en un caso una papa y en el otro un espigón de maíz. Estos amuletos se llaman sasiyu y están destinados a traer suerte y abundancia para la casa (Figura 22). Como última operación amarran los travesaños a las $\mathrm{V}$ puestos al revés de las armaduras. Terminado todo esto sacan las dos sogas auxiliares arriba mencionadas y ponen al lado exterior del muro, la cima, donde están clavadas las partes bajas de las ligas de construcción del techo, una fila de adobes para hacer más firme toda la construcción, para que no se mueva. Estos adobes los ponen sobre una capa de argamasa de barro.

Después de terminar estos trabajos empieza el proceso propio de techar. Tres hombres quitan un poco una faja de la calamina $p$ 'ira, la levantan en un lado hasta ponerla de lado a lo largo. Después ponen debajo de la faja dos barras largas antes preparadas, ponen la faja sobre ellas, al revés con la parte de abajo hacia arriba, la levantan sobre estas barras y la entregan a dos hombres sobre las armaduras. Éstos colocan la faja sobre la construcción, de modo que el lado ancho está apoyado sobre la fila superior de los adobes mencionada arriba; el lado superior se dobla algunos 20 centímetros sobre el caballete para el otro lado del techo. Así siguen techando desde un lado al otro, dejando que cada faja siguiente sobrepase un poquito la anterior. Los hombres empiezan siempre el trabajo de techar primero la parte a sotavento, para que no se deje entrar el viento bajo el techo, lo que es de suma importancia en esta región de vientos y ventarrones $\tan$ frecuentes y fuertes.

Las fajas de la p'ira no se aseguran de ninguna manera; se mantienen por su peso propio en su lugar. Cuando todo el techo está cubierto, echan sobre toda la superficie del techo una capa de paja brava suelta, de calidad inferior, de segunda clase, muy frecuentemente desde un techo viejo desmontado o caído, una capa regular de unos 20 centímetros de espesor.

Después de terminar este trabajo llega el turno a los manojos preparados de paja ichu nueva y derecha, sacada desde el terreno con raíces. Para cubrir un techo de tamaño mediano se necesitan diez cargas de paja, esto significa veinte manojos ligados por 


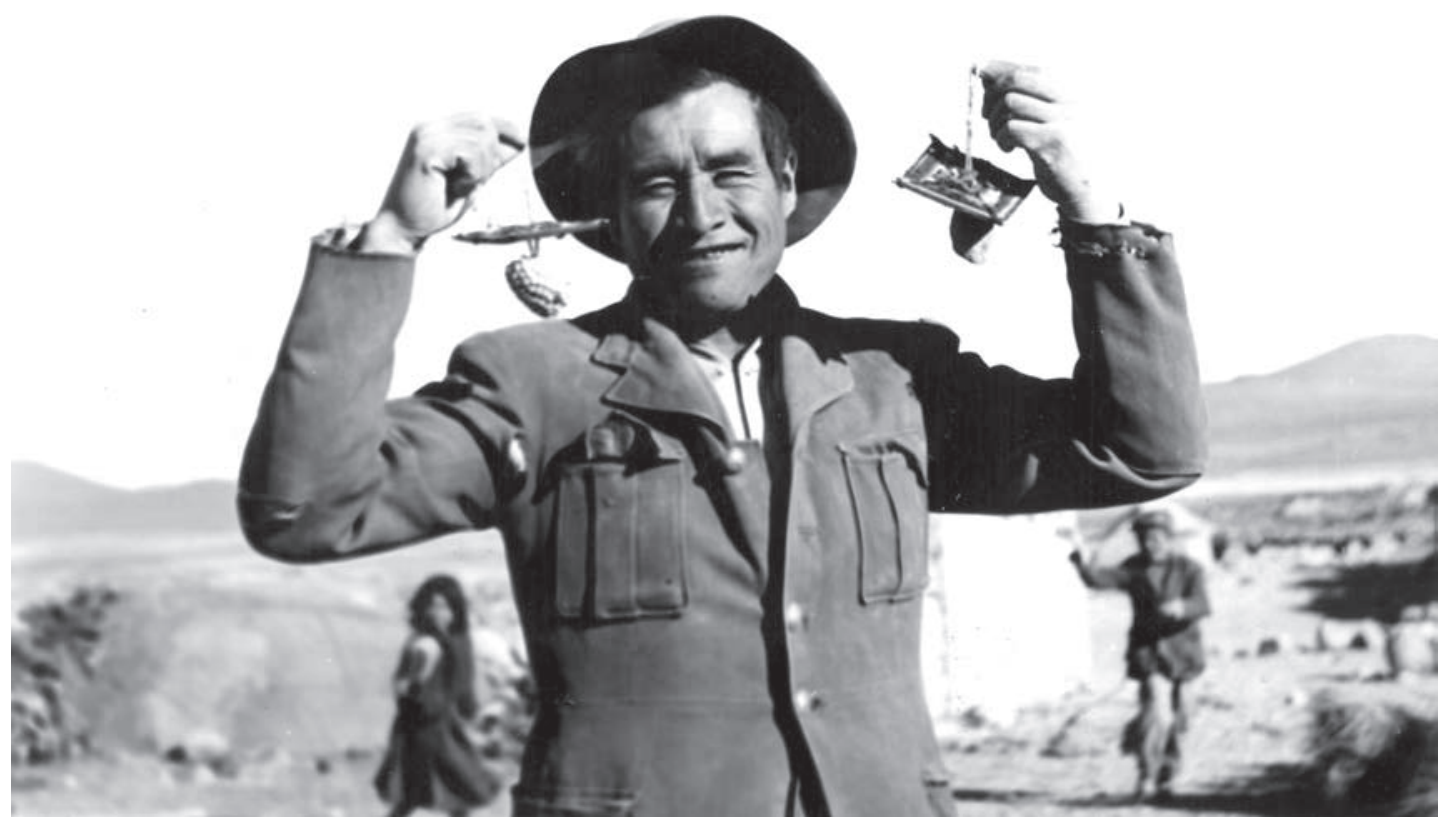

Figura 22. Amuletos llamados sasiyu.

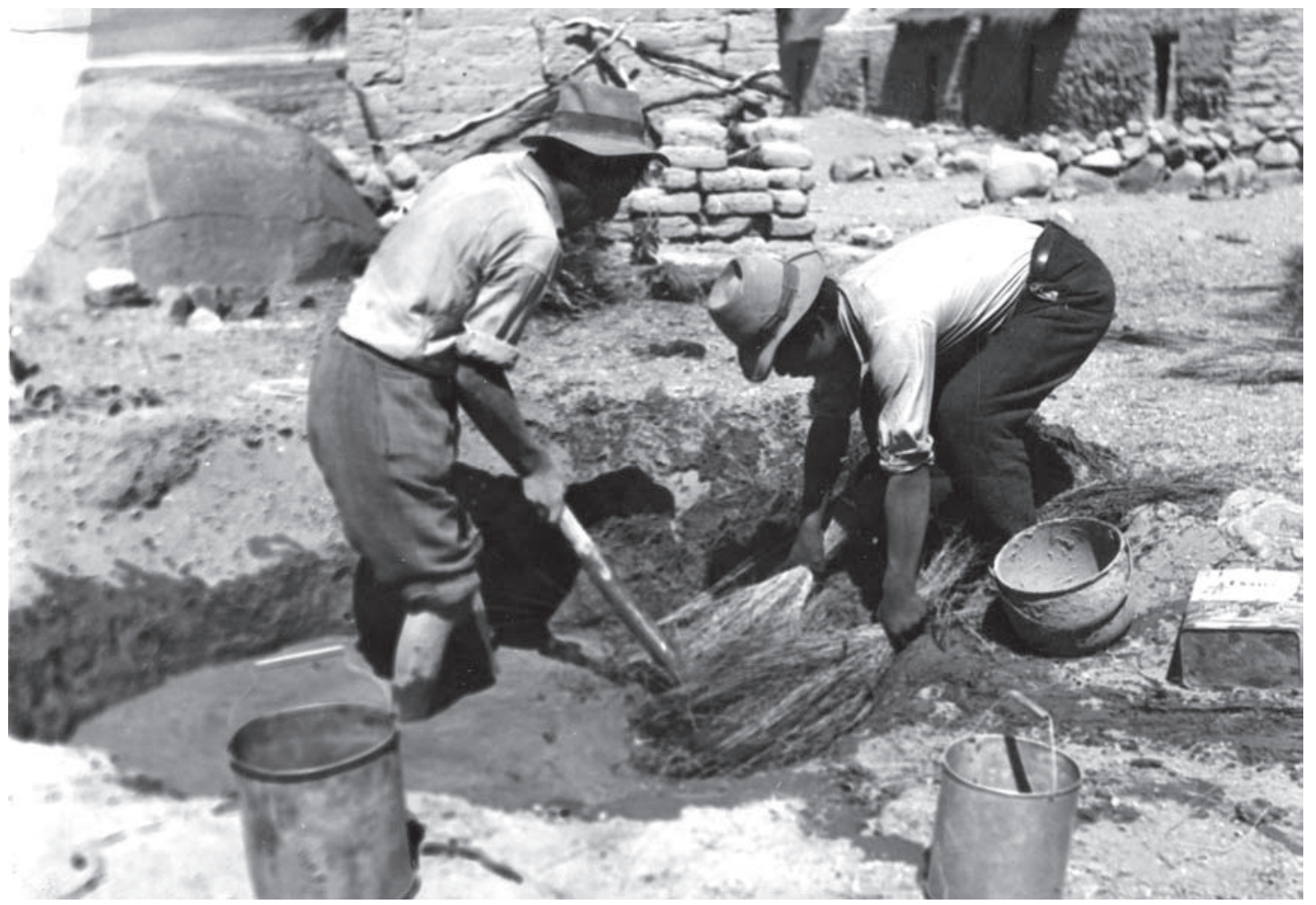

Figura 23. Los hombres mojan la paja en el barro. 
la soga, de un diámetro de unos 60 centímetros. De estos manojos sacan puñados bastante grandes, los empuñan por la parte superior y la parte baja, con raíces, los mojan en el hoyo con barro poco consistente (Figura 23). La paja remojada y con barro la llevan los ayudantes a los que están techando. Los techadores empiezan a poner estos puñados sobre la fila superior de adobes puestos de manera plana, con la parte mojada hacia dentro, y después sobre esta capa de paja, empezando desde abajo, siempre con la parte mojada y con barro hacia arriba, para regar la paja y para mantenerla junta (Figura 24). La parte mojada siempre la doblan un poco en sus manos y las partes opuestas, delgadas y secas las meten ligeramente en la capa baja, para que la superficie del techo quede bien arreglada, lisa.

Así continúan hacia arriba, hacia el caballete. Llegando al caballete doblan los puñados fuertemente sobre la parte superior. Terminada una faja aproximadamente de un metro de largo la limpian con un palo, agitándolo en la dirección hacia abajo y empiezan desde abajo otra faja. Colocada la parte baja, capa primera horizontal, rellenan por costumbre el ángulo o espacio así formado con más paja de segunda calidad. Esta sirve como aislante y arregla la transición en las capas de paja larga superior. Después continúan techando como hemos visto antes. Las capas sobresalen una a la otra por unos 20 centímetros.

El trabajo de techar lo realizan regularmente dos hombres. Cada uno trabaja en una parte y se juntan en el centro. Uno de ellos después baja y el trabajador restante rellena el espacio del resto [que queda], manteniéndose con cuidado a las partes terminadas y cambiando sus piernas en un lugar. Así arregla primero la parte a sotavento del techo y después la parte de babor, más expuesta al viento. El caballete lo hacen más firme poniendo sobre él los restos, pedazos doblados de la calamina p'ira, doblados en la forma de una gotera. La techadura de este tipo tiene una duración de diez a doce años.

En algunos casos, especialmente en los lugares del pueblo que son muy expuestos al viento y tienen que resistir a los ventarrones fortísimos, hay que hacer el techo más resistente. En estos casos hemos observado que los campesinos complementan la cubierta de paja con una capa superior de barro de poca consistencia, para aplastar la paja ichu mejor a la construcción de la armadura y a la p'ira. El barro lo aplican al techo directamente con las manos. Lo

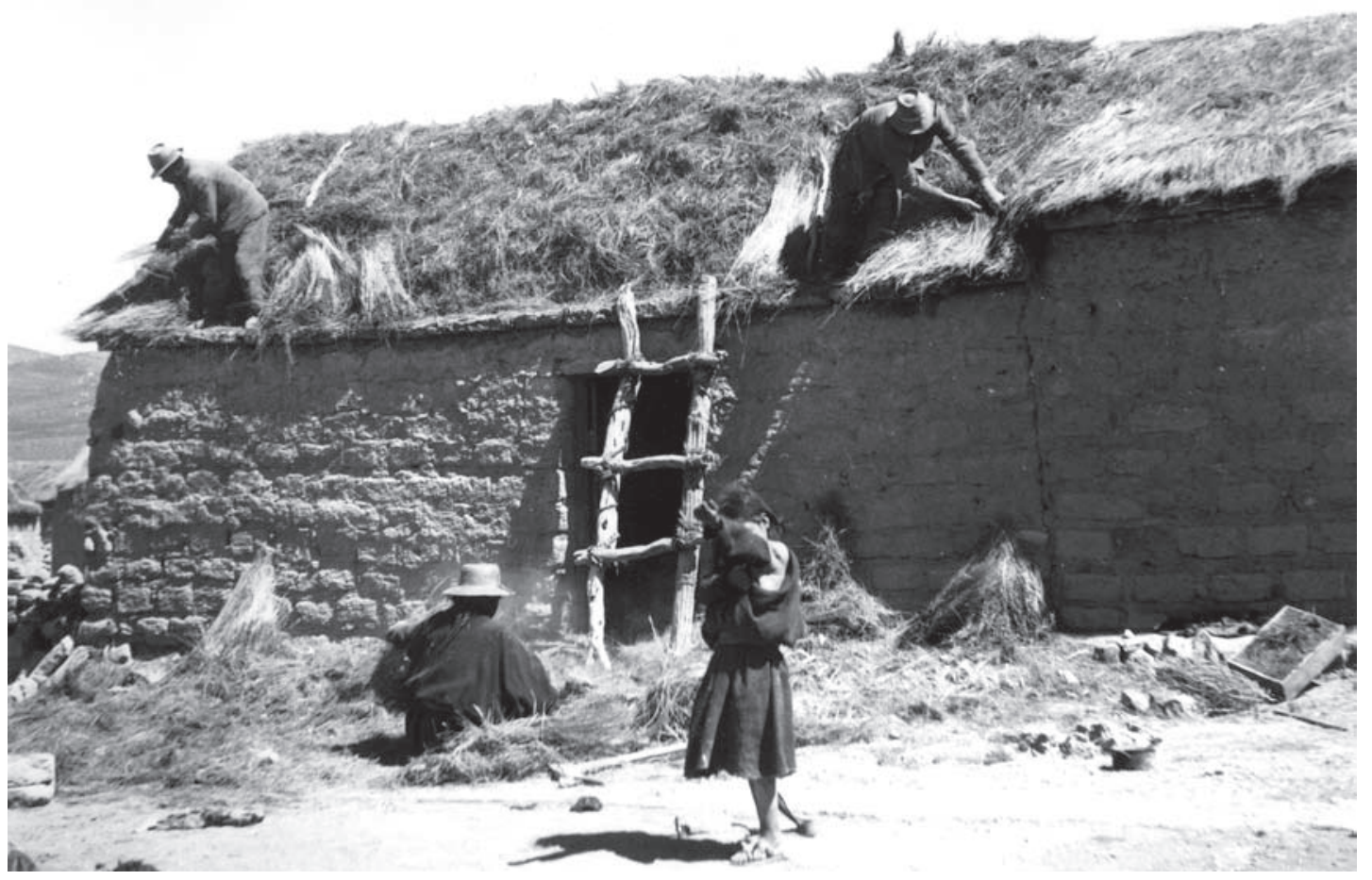

Figura 24. Los techadores. 
hace un trabajador ubicado cuidadosamente sobre la parte marginal del muro de la casa o en los lugares donde se juntan las vigas de la armadura. Para este trabajo se necesita un ayudante, quien trae el barro a su compañero en una lata.

Para terminar la construcción del techo y así también de toda la casa hay que levantar en la parte central del caballete una cruz (Figura 8), como protección religiosa y mágica de la casa contra los espíritus malos y especialmente contra el rayo, $\tan$ frecuente durante tempestades del invierno del Altiplano. La cruz la hacen de dos palitos (de altura de unos 30 centímetros), atados con un pedacito de correhuela de cuero remojado. La cruz está complementada por dos ramilletes de paja o totora seca, amarrados juntos en la parte baja de la cruz con un poco de lana roja y después cada ramillete en una extremidad de un brazo de la cruz, también con lana roja. Estos ramilletes pueden interpretarse que sirven como símbolos de las herramientas del martirio de Jesucristo o también puede ser, que sirven solamente como adornos de la cruz. Los indios mismos lo hacen por costumbre y no saben explicarlo. La cruz la estabilizan además con unos huecos de la mano de barro [sic].

Con la cruz puesta está ya la casa casi lista para habitarla. Falta solamente una ofrenda para traer suerte a los habitantes de la casa. Para esta finalidad hay que matar de manera ceremonial a un animal, una oveja o llama (Figura 25) o también, en el caso de pobreza de los dueños, una gallina y echar un poco de la sangre al muro, al lado derecho de la puerta. Lo mismo se hace con un poco de alcohol, murmurando bendiciones. Después hay que preparar para los amigos y ayudantes una comida de carne con papas y con bastante alcohol pusitunka.

El interior de las casas es muy simple. En la mayoría de ellas no hay prácticamente muebles. Una mesa es cosa extraordinaria. La he visto solamente en pocas casas. Igualmente excepcional es un banco o una silla. En cada casa existe una plataforma baja de piedras y barro, que sirve en la

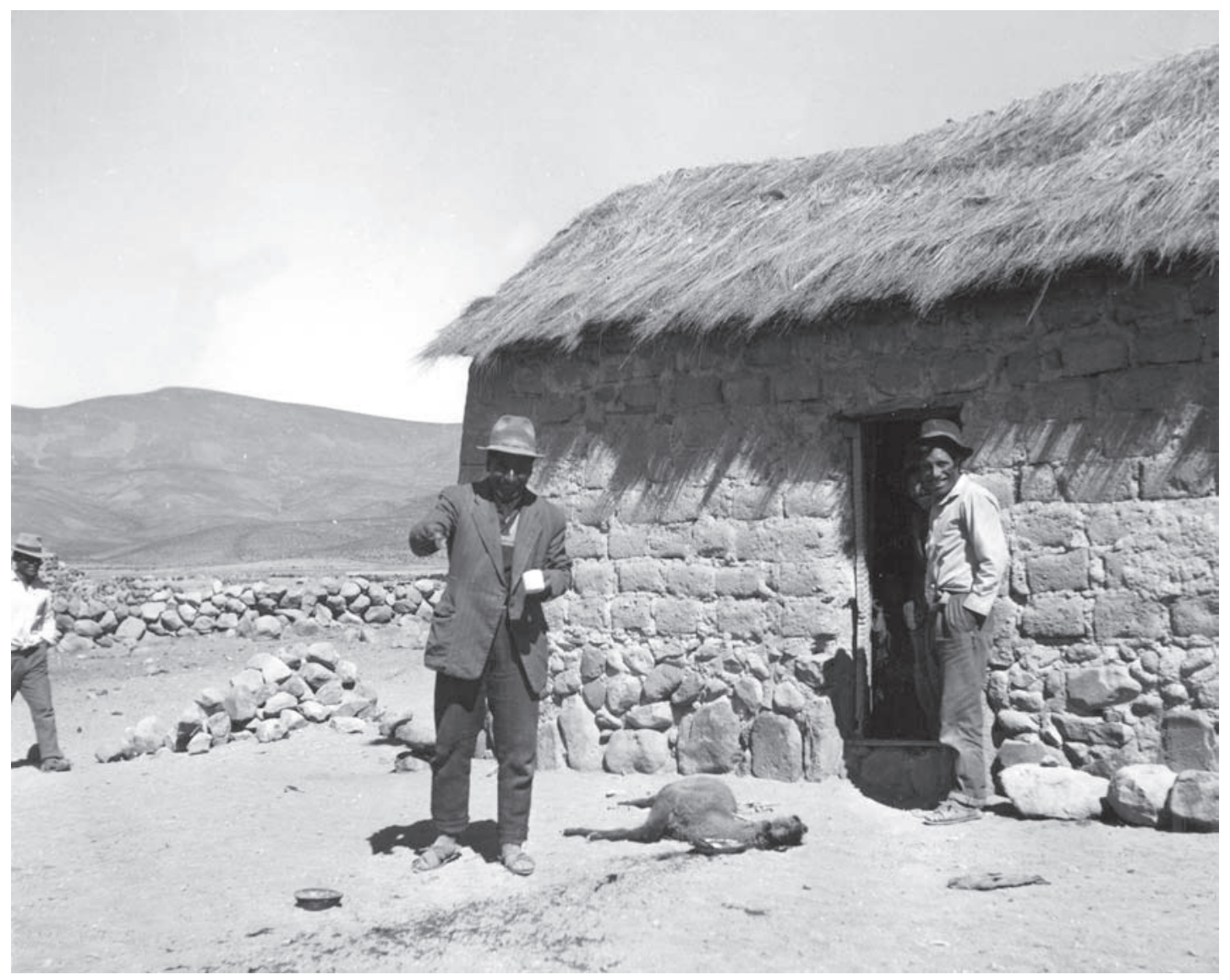

Figura 25. Ofrenda de una llama joven en la ocasión de la inauguración de una casa nueva. 
noche como cama para dormir y durante el día para sentarse. Su altura es entre 30 y 40 centímetros y está cubierta con cueros secos de ovejas o llamas y sobre este fondo con unas frazadas de lana de fabricación doméstica. En los dormitorios existen habitualmente dos plataformas de este tipo, a ambos lados de la puerta. En el centro de la casa hay un fogón, puesto al muro, construido de dos filas paralelas de piedras gruesas.

La plataforma-cama continúa en la mayoría de las casas en una forma más estrecha junto a otro muro de la casa y está destinada para sentarse de manera cómoda, en la forma de un banco. Para guardar ropa y otras cosas sirven estacas de madera, empotradas en los muros en la altura de 1,8 hasta 2 metros. Para guardar ropa de mujeres sirve corrientemente una soga tendida sobre dos estacas, desde un muro largo al otro, encima de la cama. En la despensa hay también una o dos plataformas como en el dormitorio. Sobre ellas ponen habitualmente sacos con papas, quinua u otros aprovisionamientos. Condimentos, coca y otras cosas u objetos más chicos los guardan en sacos de lana llamados talejas [talegas], colgados sobre las estacas empotradas en los muros durante la fabricación de las casas. En pocos casos sirven para guardar cosas unos cajones simples. También la cocina tiene su plataforma-cama, al lado del fogón.

En la mayoría casi absoluta de las casas más nuevas y en todas las casas de tipo más antiguo existen en los muros -tradicionalmente en los muros más cortos- pequeños nichos, llamados phutu, de tamaño aproximadamente de 30 por 30 centímetros, donde guardan la luz, lamparitas primitivas de kerosén o las de tipo más antiguo, llamadas mechachúas y fósforos. Este nicho phutu es un fenómeno muy antiguo, de origen preincaico. Se puede encontrar ya en las ruinas de las casas en Tiwanaku y en otros lugares con restos arqueológicos en Bolivia y también en el Altiplano chileno ${ }^{4}$.
Como adorno interno de las casas sirve habitualmente el revoque del interior, en pocos casos pintado con el color blanco. En otras casas pegaron a los muros interiores en calidad de decoración, páginas de las revistas ilustradas, como papel de empapelar o calendarios grandes con dibujos patrióticos de colores. En algunas casas hemos observado que tienen como decoración del interior invitaciones para fiestas del pueblo, impresas en Bolivia, donde anuncian su función de "pasantes", recuerdos de fiestas pasadas que dan mucho prestigio a la familia. Estas invitaciones o avisos se presentan frecuentemente en un marco de papel duro rojo, adornado por ornamentos dorados de imprenta o de flores artificiales de varios colores o también con pedacitos de espejos, engastados en el marco mismo. Grabados de santos patrones y cruces no hemos visto.

Las casas necesitan frecuentemente reparaciones, especialmente después de la época de lluvias. Los muros se reparan de manera primitiva con barro. Los techos se arreglan con un poco de paja nueva o reemplazando unos pedazos de calamina p'ira. El revoque y la pintura exterior se reparan solamente excepcionalmente.

En la casa hacen la limpieza aproximadamente una vez en el mes, barren de manera superficial con una escoba primitiva de paja brava. Las camas se arreglan muy pocas veces. Habitualmente solo cuelgan las frazadas mejores a la soga antes mencionada.

En el pueblo no existen calles en el exacto sentido de la palabra. Las casas están ordenadas en grupitos o en filas. Orientadas norte-sur, con frente y puerta casi sin excepción hacia la salida del sol. Los indios tienen para el futuro el plan de reconstruir unas partes de la población para tener en su pueblo una plaza verdadera frente a la iglesia y una calle principal orientada este-oeste, comunicación principal.

\section{Notas}

1 Taberna, F.G.: Los Andes y el Altiplano Tarapaqueños. Trab. de Memoria 1968.

2 Quiero agradecer en este lugar por una ayuda muy eficaz y amistosa a la señora Lotte Weisner de la Sociedad Antropológica de Chile, que durante su estadía en Enquelga colaboró conmigo en la clasificación de las casas.
Con el Dr. Meter Neumann del Museo Estatal de Etnología de Dresde (RDA) y con la Dra. Olga Píchová Kandertová del Museo Náprstek de Praga (1966).

4 Šolc, V.: Los Aymaras de las islas del Titicaca, México 1969. Cáp. 5. 